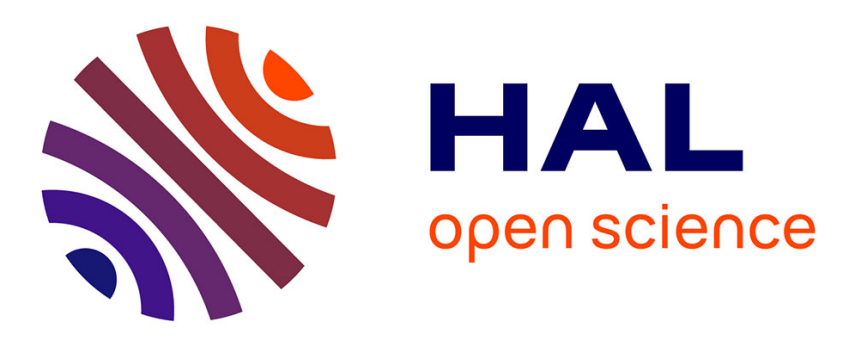

\title{
Effect of surface roughness, porosity and roughened micro-pillar structures on the early formation of microbial anodes
}

Pierre Champigneux, Cyril Renault-Sentenac, David Bourrier, Carole Rossi, Marie-Line Délia-Dupuy, Alain Bergel

\section{To cite this version:}

Pierre Champigneux, Cyril Renault-Sentenac, David Bourrier, Carole Rossi, Marie-Line DéliaDupuy, et al.. Effect of surface roughness, porosity and roughened micro-pillar structures on the early formation of microbial anodes. Bioelectrochemistry, 2019, 128, pp.17-29. 10.1016/j.bioelechem.2019.03.002 . hal-02279662

\section{HAL Id: hal-02279662 \\ https://hal.science/hal-02279662}

Submitted on 5 Sep 2019

HAL is a multi-disciplinary open access archive for the deposit and dissemination of scientific research documents, whether they are published or not. The documents may come from teaching and research institutions in France or abroad, or from public or private research centers.
L'archive ouverte pluridisciplinaire HAL, est destinée au dépôt et à la diffusion de documents scientifiques de niveau recherche, publiés ou non, émanant des établissements d'enseignement et de recherche français ou étrangers, des laboratoires publics ou privés. 


\section{OATAO}

Open Archive Toulouse Archive Ouverte

\section{Open Archive Toulouse Archive Ouverte}

OATAO is an open access repository that collects the work of Toulouse researchers and makes it freely available over the web where possible

This is an author's version published in: http://oatao.univ-toulouse.fr/24221

Official URL: https://doi.org/10.1016/j.bioelechem.2019.03.002

\section{To cite this version:}

Champigneux, Pierre $\leftrightarrows$ and Renault-Sentenac, Cyril and Bourrier, David and

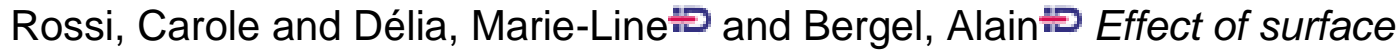
roughness, porosity and roughened micro-pillar structures on the early formation of microbial anodes. (2019) Bioelectrochemistry, 128. 17-29. ISSN $1567-5394$

Any correspondence concerning this service should be sent to the repository administrator: tech-oatao@listes-diff.inp-toulouse.fr 


\title{
Effect of surface roughness, porosity and roughened micro-pillar structures on the early formation of microbial anodes
}

\author{
Pierre Champigneux ${ }^{\mathrm{a}}$, Cyril Renault-Sentenac ${ }^{\mathrm{b}}$, David Bourrier ${ }^{\mathrm{b}}$, Carole Rossi ${ }^{\mathrm{b}}$, \\ Marie-Line Delia ${ }^{a}$, Alain Bergel ${ }^{\mathrm{a}, *}$ \\ a Laboratoire de Génie Chimique, Université de Toulouse, CNRS, INPT, UPS, Toulouse, France \\ ${ }^{\mathrm{b}}$ Laboratoire d'Analyse et d'Architecture des Systèmes CNRS, Université de Toulouse, 7 avenue du colonel Roche, 31031 Toulouse, France
}

Keywords:

Bioanode

Geobacter sulfurreducens

Gold

Microbial fuel cell

Bioelectrochemical system

\begin{abstract}
A B S T R A C T
The early formation of electroactive biofilms was investigated with gold electrodes inoculated with Geobacter sulfurreducens. Biofilms were formed under an applied potential of $0.1 \mathrm{~V} / \mathrm{SCE}$, with a single batch of acetate $10 \mathrm{mM}$, on flat gold electrodes with different random surface roughness. Roughness with arithmetical mean height $\left(\mathrm{S}_{\mathrm{a}}\right)$ ranging from 0.5 to $6.7 \mu \mathrm{m}$ decreased the initial latency time, and increased the current density by a factor of 2.7 to 6.7 with respect to nano-rough electrodes $\left(S_{a}=4.5 \mathrm{~nm}\right)$. The current density increased linearly with $S_{a}$ up to $14.0 \mathrm{~A} \cdot \mathrm{m}^{-2}$ for $S_{a}$ of $6.7 \mu \mathrm{m}$. This linear relationship remained valid for porous gold. In this case, the biofilm rapidly formed a uniform layer over the pores, so porosity impacted the current only by modifying the roughness of the upper surface. The current density thus reached $14.8 \pm 1.1 \mathrm{~A} \cdot \mathrm{m}^{-2}$ with $\mathrm{S}_{\mathrm{a}}$ of $7.6 \mu \mathrm{m}(7$ times higher than the nano-rough electrodes). Arrays of 500- $\mu \mathrm{m}$-high micro-pillars were roughened following the same protocol. In this case, roughening resulted in a modest gain around 1.3-fold. A numerical model showed that the modest enhancement was due to ion transport not being sufficient to mitigate the local acidification of the structure bottom.
\end{abstract}

\section{Introduction}

Over the past fifteen years, the electroactive properties of microorganisms have motivated a profusion of inspiring work. In the domain of microbial electrochemical technologies [1,2], microbial anodes are the core element of many innovative processes [3], such as microbial fuel cells [4], microbial electrolysis cells for hydrogen production [5], methane synthesis [6] or metal recovery [7], passive systems such as the microbial snorkel for environmental bioremediation [8], various kinds of biosensors $[9,10]$, etc.

Beyond the framework of microbial electrochemical technologies, electroactive biofilms are at work in microbial corrosion [11], and microbial anodes have been envisioned as a possible way to inhibit corrosion [12]. Electroactive species have also been used as markers of surface biofouling $[13,14]$. The early detection of electroactivity has successfully been implemented for monitoring equipment biofouling in marine and fresh water environments [15]. In this case, the sensors were based on cathodic catalysis but, given the ubiquity of exoelectrogenic species [16,17], there is no doubt that anodic sensors will also be developed in the future to investigate or monitor environmental biofilms.

\footnotetext{
* Corresponding author.

E-mail address: alain.bergel@ensiacet.fr (A. Bergel).
}

In this very broad context, the research community is still facing an important gap in basic knowledge when the objective is to control the electrode/bacteria interface. The predominant role of electrode topography has been pointed out in many studies [18-26] and in a recent review article [27], but controversial results have been reported. For instance, surface roughness has sometimes been reported as the main parameter that impacts the current density produced by microbial anodes, being even more important than the anode material itself [28]. In contrast, in the case of stainless steel electrodes, $5 \mu \mathrm{m}$ roughness has shown no positive effect vs. a smooth surface [22]. In another study, stainless steel electrodes inoculated with Geobacter sulfurreducens showed increased biofilm coverage and current production when the average surface roughness was increased from 2 to $4 \mu \mathrm{m}$, while no effect was observed at lower values, from 0.1 to $2 \mu \mathrm{m}$ [23]. A third study, which used flame oxidation to increase the roughness of stainless steel electrodes from 75 to $151 \mathrm{~nm}$, reported higher current and better biofilm coverage with higher roughness [29].

These examples illustrate the extreme variability of the effect of roughness reported in the literature. This situation is, to a great extent, due to the concomitant variation of roughness and other surface parameters. Variation of roughness is often linked to the variation in surface chemistry, which depends on the technique used to modify the roughness. It is consequently difficult to unravel the impact of the surface topography from that of other surface parameters, and notably those 
related to chemical modification of the surface [29]. For these reasons, several research teams have turned to surface structuration as a way to control the surface topography by minimizing the changes of other surface properties [30-34].

We have recently implemented surface structuring of gold electrodes to compare the nano-rough surface $\left(R_{a}=4.5 \mathrm{~nm}\right)$, either flat or structured with 500- $\mu \mathrm{m}$-high micro-pillars [34]. The current density produced was increased from 2 to $8.5 \mathrm{~A} \cdot \mathrm{m}^{-2}$ by the micro-pillars. This current increase was attributed to the larger surface area available for biofilm development, due to the micro-pillars.

Here, the same experimental approach was implemented in order to assess the impact of random roughness at the micrometre level. As previously, gold electrodes were used because gold is a suitable electrode material for forming efficient microbial anodes [35-38] and it allows accurate control of the surface topography, while keeping similar surface chemical properties. In is thus possible to focus on the impact of the electrode topography by avoiding variation of other surface parameters. As previously, electrodes were colonized by Geobacter sulfurreducens, a widely-used model electroactive bacterium [39].

Attention was focused on the early stage of biofilm formation. Early formation is the phase when there are the most opportunities to act on the biofilm properties. It is consequently important to progress in understanding this key phase and to identify the parameters that can impact it, if the objective is to establish basic guidelines for electroactive biofilm design. The early stage of biofilm formation is the phase where levers are most likely to be found, not only to enhance electroactive properties, but also to mitigate them, as in the context of microbial corrosion or biofouling. Mastering the early formation of electroactive biofilms is also essential to decrease the response time and the detection threshold of sensors based on the detection of microbial electroactivity.

The previous study dealt with surface structuring in the form of 500$\mu \mathrm{m}$-high micro-pillars [34]. The present study completes the range of surface topographies in three ways:

- random roughness ranging from 0.5 to $6.7 \mu \mathrm{m}$ was elaborated on flat electrodes by using gold electrodeposition,

- the same gold electrodeposition protocol was pushed to create a thick porous layer with pore sizes from a few to around $50 \mu \mathrm{m}$,

- the random roughness was elaborated on the electrode surface that had previously been structured with the 500 - $\mu \mathrm{m}$-high micro-pillars.

- The sum of the two studies gives a comprehensive view of the impact of surface topography over a very wide range.

Finally, it would be useful to emphasize a general comment on the results provided by the present work. It is shown here that random micrometre-sized surface roughness has a great impact on the current produced by microbial anodes. This roughness size can be achieved unintentionally when treating, modifying or coating an electrode surface. Consequently, micrometre-sized roughness should now be considered as a key parameter in the assessment of any electrode surface modification. When comparing the performance of a non-treated, control electrode with a treated, modified or coated electrode, the possible variation of the surface roughness must be assessed first, before concluding on the possible impact of other parameters related to the interface modification. Beyond the specific results described below, this general warning should be one of the major conclusions of the study.

\section{Materials and methods}

\subsection{Preparation of gold electrode with different surface roughness values}

Nano-rough gold (NG) surfaces $1 \mathrm{~cm}^{2}$ in area were formed on $\mathrm{Si}$ (100), P-type silicon wafers. The electrodes were formed by evaporation of a $250 \mathrm{~nm}$ thick gold layer followed by electrolytic deposition of gold to achieve a $1.75 \mu \mathrm{m}$ thick gold layer. The average roughness, measured by AFM, was $4.5 \mathrm{~nm}$ for the NG surfaces.
Random micro-rough gold (MG) was formed by electrolytic growth of an additional gold layer on the NG surfaces. The NG surfaces were immersed in a bath of chloroauric acid $\left(\mathrm{HAuCl}_{4}, 2 \mathrm{mM}\right)$ and sulfuric acid $\left(\mathrm{H}_{2} \mathrm{SO}_{4}, 96 \%, 2 \mathrm{mM}\right)$. Four different current densities were applied: $0.35,0.69,1.39$ and $2.08 \mathrm{~A} \cdot \mathrm{m}^{-2}$, which led to 4 different surface topographies named MG-1 to MG-4. The MG surfaces were then mounted on polychlorobiphenyl (PCB) supports. The gold surface was connected to the contact pad of the PCB using a KnS 4526 micro-welding machine and electrical contacts were insulated with biocompatible silicon (Loctite 4562).

Porous gold (PG) was formed following the same protocol at a high rate using $5 \mathrm{~A} \cdot \mathrm{m}^{-2}$ for $10 \mathrm{~min}$. The porous structure obtained was around $100 \mu \mathrm{m}$ thick, measured with a TENCOR P16 mechanical profilometer. Three similar electrodes were made in this way.

Micro-pillar arrays with micro-rough surface ( $\mu \mathrm{P}-\mathrm{MG})$ : surface micro-structuring was performed on Si (100) P-type silicon wafers with an epoxy resin (SU-8 3050, MicroChem Corp) patterned by photolithography to form the pillar array. The array consisted of square pillars $100 \mu \mathrm{m}$ wide and $500 \mu \mathrm{m}$ high, spaced $200 \mu \mathrm{m}$ apart. The structured electrodes had 1156 pillars on a $1 \mathrm{~cm}^{2}$ surface. A first metallization was performed by sputtering $\mathrm{Cu} / \mathrm{Cr}$ and then smooth electrolytic deposition of gold to create the usual NG gold layer with $4.5 \mathrm{~nm}$ roughness. Then the surface of the micro-pillars was roughened by electrolytic deposition of gold, performed for 10 min at three different current densities: two electrodes were roughened by electrodeposition at $0.8 \mathrm{~A} \cdot \mathrm{m}^{-2}(\mu \mathrm{P}-\mathrm{MG}-1)$, one at $1.5 \mathrm{~A} \cdot \mathrm{m}^{-2}(\mu \mathrm{P}-\mathrm{MG}-2)$ and another at $2.1 \mathrm{~A} \cdot \mathrm{m}^{-2}(\mu \mathrm{P}-\mathrm{MG}-3)$.

\subsection{Electrochemical set-up}

Colonization of the gold surfaces was carried out in tightly sealed $500 \mathrm{~mL}$ reactors, filled with $300 \mathrm{~mL}$ solution and continuously sparged with $\mathrm{N}_{2}: \mathrm{CO}_{2}$ (80:20). The gas bubbling was carefully arranged to avoid any disturbance on the working electrode. A water-bath kept the temperature steady at $30{ }^{\circ} \mathrm{C}$. The experiments were performed with 3-electrode set-ups in single compartment reactors. The auxiliary electrode was a platinum grid (Heraeus SAS, Germany) and a saturated calomel electrode was used as the reference (SCE, potential $+0.24 \mathrm{~V} / \mathrm{SHE}$ ). The gold surfaces were mounted and welded onto a PCB support and connected to the potentiostat. The bioanodes were formed under constant polarization at $0.1 \mathrm{~V} / \mathrm{SCE}$ (VSP potentiostat, Bio-Logic SA, France) and the current densities were recorded throughout the experiment every $10 \mathrm{~min}$. Cyclic voltammetries at $1 \mathrm{mV} \cdot \mathrm{s}^{-1}$ were performed before inoculation and when the current was close to reaching a maximum.

The electroactive biofilms were formed under constant polarization at $0.1 \mathrm{~V} / \mathrm{SCE}$ in 4 different runs. Each run corresponded to four or five reactors run in parallel and inoculated with the same pre-culture of Geobacter sulfurreducens:

- run \#1: 4 reactors with the MG-1 to MG-4 micro-rough surfaces and 1 reactor with the nano-rough (NG) surface used as a control,

- run \#2: identical to run \#1,

- run \#3: 3 reactors with the PG surface and 2 reactors with the NG surface used as a control,

- run \#4: 4 reactors with micro-rough micro-pillar arrays, $\mu \mathrm{P}-\mathrm{MG}-1$ to $\mu \mathrm{P}-\mathrm{MG}-3$.

The current densities were expressed with respect to the $1 \mathrm{~cm}^{2}$ projected surface area of the gold surfaces. The chronoamperograms (current density vs. time) were characterized by three parameters: the maximum current density reached $\left(J_{\max }, A \cdot \mathrm{m}^{-2}\right)$, the starting time ( $t_{\text {start }}$, days), defined as the time required for the current to reach $10 \%$ of $J_{\max }$, and the current density increase rate $\left(r_{i}, A \cdot m^{-2} \cdot d^{-1}\right)$, which was calculated as the average value of the slope of the current density vs. time over 1 day around the inflection point of the curve. Maximum current densities were recorded by checking that the 
maximum value was reached during at least 18 records during the chronoamperogramms, which represented a duration of at least $3 \mathrm{~h}$ (record every $10 \mathrm{~min}$.). According to the $10 \mathrm{~min}$ frequency current recording, the experimental error of the starting time values was $\pm 0.01 \mathrm{~d}$.

\subsection{Inocula and media}

Geobacter sulfurreducens (ATCC 51573) purchased from DSMZ was grown in specific growth medium that contained, per litre: $0.1 \mathrm{~g} \mathrm{KCl}$, $1.5 \mathrm{~g} \mathrm{NH}_{4} \mathrm{Cl}, 2.5 \mathrm{~g} \mathrm{NaHCO}_{3}, 0.6 \mathrm{~g} \mathrm{NaH}_{2} \mathrm{PO}_{4}$, and $0.82 \mathrm{~g} \mathrm{CH}_{3} \mathrm{COONa}$. The medium was sterilized by autoclaving at $121^{\circ} \mathrm{C}$ for $20 \mathrm{~min}$. After sterilization, the medium was completed with $8 \mathrm{~g} / \mathrm{L}$ sodium fumarate filtered at $0.22 \mu \mathrm{m}, 10 \mathrm{~mL} / \mathrm{L}$ Wolfe's vitamin solution (ATCC MD-VS) and $10 \mathrm{~mL} / \mathrm{L}$ modified Wolfe's minerals (ATCC MD-TMS). A pre-culture of G. sulfurreducens was prepared for 3 days in a fresh deoxygenated culture medium $\left(2 \% \mathrm{v} / \mathrm{v}, 30{ }^{\circ} \mathrm{C}\right)$ to reach a final absorbance of around 0.4 at $620 \mathrm{~nm}$. Reactors were filled with growth medium, vitamin solution and modified Wolfe's minerals and constantly sparged with $\mathrm{N}_{2}: \mathrm{CO}_{2}$ (80:20). After 20 min of deoxygenation under open circuit potential, the electrodes were characterized by an initial cyclic voltammetry. Then, reactors were inoculated with the pre-culture. The inoculation volume was adjusted to obtain the cell density in each reactor that corresponded to an inoculation ratio of $10 \% \mathrm{v} / \mathrm{v}$ with an inoculum at 0.4 absorbance. After the inoculation, acetate $10 \mathrm{mM}$ was added to the medium as the sole electron donor; no fumarate was present.

\subsection{Microscopic imaging and electrode characterization}

The clean electrode surfaces were observed on a Hitachi S-4800 scanning electron microscope (SEM) in low vacuum mode at an accelerating voltage of $15 \mathrm{kV}$ and an intensity of $15 \mu \mathrm{A}$. Various magnifications and locations were used to characterize the surfaces. The surface roughness was characterized by the spatial arithmetical mean height $\left(S_{a}\right)$ measured with a non-contact 3D optical profiler (S-Neox, Sensofar). The values were averaged over $20 \%$ of each surface.

The electrochemically active surface area $\left(A_{e}\right)$ was measured following the technique described by Burke and Nugent [40]. The electrodes were first soaked in an $\mathrm{H}_{2} \mathrm{O}_{2} / \mathrm{H}_{2} \mathrm{SO}_{4}$ (1:3) solution to reduce the hydrophobicity and thus avoid gas retention on the surface during the measurement. Cyclic voltammetry was performed between 0 and $1.8 \mathrm{~V} / \mathrm{SCE}$ in $\mathrm{H}_{2} \mathrm{SO}_{4} 0.5 \mathrm{M}$, following two successive phases: firstly, 25 cycles were performed at $500 \mathrm{mV} \cdot \mathrm{s}^{-1}$ in order to clean the surface, then 25 cycles were performed at $50 \mathrm{mV} \cdot \mathrm{s}^{-1}$ for the measurement. A reduction peak appeared between 0.8 and $0.9 \mathrm{~V} / \mathrm{SCE}$, which was assumed to be due to the formation of a monolayer of gold oxide. The charge related to the peak $(Q, \mu C)$ was calculated by integration and was linked to the electrode surface area $\left(A_{e}, \mathrm{~cm}^{2}\right)$ with the equation:

$A_{e}=\frac{Q}{C F}$

where $\mathrm{CF}=386 \mu \mathrm{C} . \mathrm{cm}^{-2}$ is the conversion factor given by Burke and Nugent for gold [40].

The technique was firstly used as proposed by Burke and Nugent with the NG electrodes. Eq. (1) gave a surface area of $2.73 \mathrm{~cm}^{2}$. This value was clearly overestimated as the projected surface area was only $1 \mathrm{~cm}^{2}$. It was extremely unlikely that the surface area would be multiplied by a factor of 2.73 with a surface roughness as low as $4.5 \mathrm{~nm}$. It was speculated that the electrodeposition technique used here to prepare the electrodes led to the formation of more than one molecular layer of oxide, while the Burke and Nugent procedure assumes that plain gold is covered by only a monolayer. Consequently, we chose to take the nano-rough electrode as the reference, by taking its electrochemically active surface area to be equal to its projected surface area of $1 \mathrm{~cm}^{2}$. Accordingly, Eq. (1) was recalibrated by using a conversion factor of $1053 \mu \mathrm{C} . \mathrm{cm}^{-2}$.
At the end of the experiments, the bioanodes were stained with Syto 9 Invitrogen, Molecular Probes) at $2.5 \mu \mathrm{M}$ for $10 \mathrm{~min}$, then carefully washed with medium and dried at ambient temperature. The electrodes were imaged with a Carl Zeiss Axiomalger M2 microscope equipped for epifluorescence with an HBO $50 \mathrm{~W}$ ac mercury light source and the Zeiss 09 filter (excitor HP450-490, reflector FT 10, Barrier filter LP520). Images were acquired with a monochrome digital camera (Evolution VF). Several different spots were imaged in order to have an appropriate representation of the general pattern of the colonization.

Epifluorescence images were analysed by greyscale interpretation to calculate the ratio of the electrode surface area covered by bacteria. The grey intensity threshold between the areas covered by the bacteria and the non-covered areas was set manually. Grey levels greater than the threshold value were considered to correspond to colonized areas, while lower grey levels were considered to show clean areas. Six images, of dimensions 866 by $645 \mu \mathrm{m}$, were treated for each electrode to determine the average coverage ratio, the edges of the electrodes being excluded to avoid the impact of side effects.

The biofilm structures were observed by scanning electron microscopy (SEM) with a Leo 435 VP-Carl Zeiss SMT. A 4\% glutaraldehyde phosphate buffer ( $400 \mathrm{mM}, \mathrm{pH} 7.4$ ) was used to fix the biofilms. The surfaces were then rinsed in phosphate buffer containing saccharose ( $400 \mathrm{mM})$. The dehydration process consisted of immersion in successive concentrations of acetone ( $50 \%, 70 \%, 100 \%$ solutions), followed by acetone and hexamethyldisilazane (HMDS) solution (50:50), and finally $100 \%$ hexamethyldisilazane. Complete evaporation of the last solution was achieved to complete the process. The samples were sputtered with a thin $(10 \mathrm{~nm}$ ) layer of gold (Scancoat Six SEM sputter coater) to guarantee their electrical conductivity.

\section{Results and discussion}

\subsection{Electrode topography of micro-rough $(M G)$ and porous $(P G)$ flat surfaces}

SEM imaging of the MG surfaces formed at 0.35 and $0.69 \mathrm{~A} \cdot \mathrm{m}^{-2}$ (MG-1 and MG-2) showed randomly distributed deposits that covered around 50 and $70 \%$ of the surface, respectively (Fig. 1). The higher electrodeposition current densities of 1.39 and $2.08 \mathrm{~A} \cdot \mathrm{m}^{-2}$ led to round craters about $10 \mu \mathrm{m}$ in diameter (MG-3 and MG-4). During the electrodeposition phase, gas bubbles evolved from the electrode surface. At the lower current densities (MG-1 and MG-2), electrodeposition was slow and the bubbles detached from the surface without impacting the deposition. For MG-3 and MG-4, gold deposition was faster and tended to entrap the bubbles in the deposited structure. This phenomenon created a crater pattern with characteristic size of around $10 \mu \mathrm{m}$.

Higher magnification showed that gold formed fir-shaped deposits of nano-dendrites on the MG- 1 and MG-2 electrodes. These nanodendrites tended to disappear on the MG-3 and MG-4, probably due to the visible densification of deposition.

All these MG surfaces showed roughness patterns added on to the NG basal surface, which remained visible at the bottom. In contrast, the PG surfaces formed at $5 \mathrm{~A} \cdot \mathrm{m}^{-2}$ showed a porous structure uniformly deposited over the whole surface area, so the basal NG surface was no longer visible (Fig. 2A). Deep pores were observed, with pore sizes ranging from a few microns to around 50 $\mu \mathrm{m}$ (Fig. 2B). The largest pores were interconnected, creating a highly porous network. The MG surfaces could be considered as 2-dimensional rough surfaces, while the PG surfaces presented a 3-dimensional porous layer with well-formed pores, which fully masked the basal surface.

For the MG surfaces, the surface area measured electrochemically $\left(A_{e}\right)$ increased with the electrodeposition current density but the increase was lower at the highest current densities, when deposition became denser (Table 1). This trend was consistent with SEM images, 

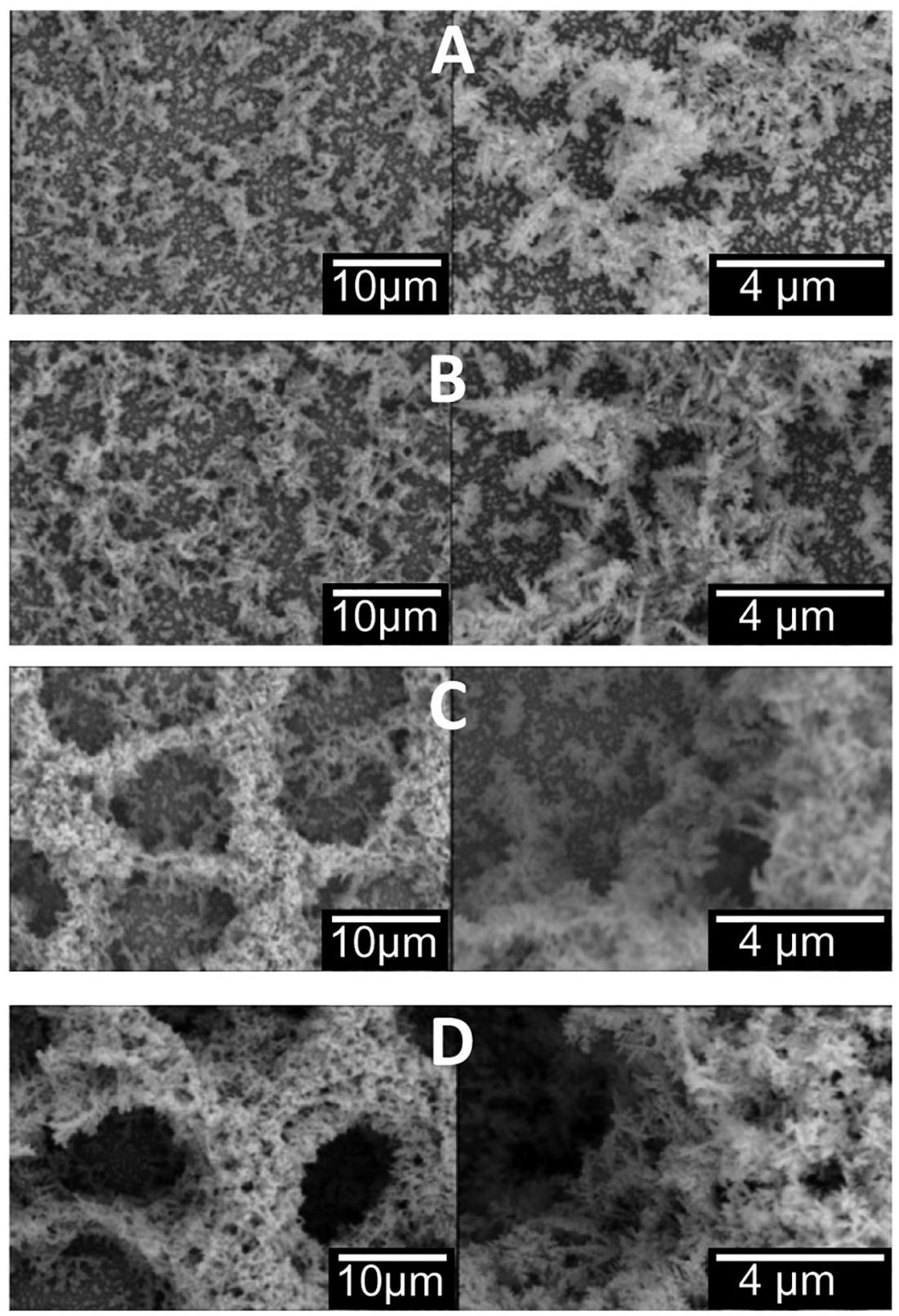

Fig. 1. SEM imaging of the micro-rough gold (MG) surfaces produced by electrodeposition with increasing current densities from MG-1 to MG4; A) MG-1, $S_{a}=0.5 \mu$ m; $B$ ) MG-2, $S_{a}=1.7$ $\left.\mu \mathrm{m} ; \mathrm{C}) \mathrm{MG}-3, \mathrm{~S}_{\mathrm{a}}=4.6 \mu \mathrm{m} ; \mathrm{D}\right) \mathrm{MG}-4, \mathrm{~S}_{\mathrm{a}}=6.7 \mu \mathrm{m}$

revealing a deposition pattern of isolated clusters of nano-dendrites at low current density, which tended to disappear with the densification of the deposition at higher current densities.

The arithmetical mean height $\left(S_{a}\right)$ of the MG surfaces increased linearly from 0.5 to $6.7 \mu \mathrm{m}$ with the electrodeposition current density,

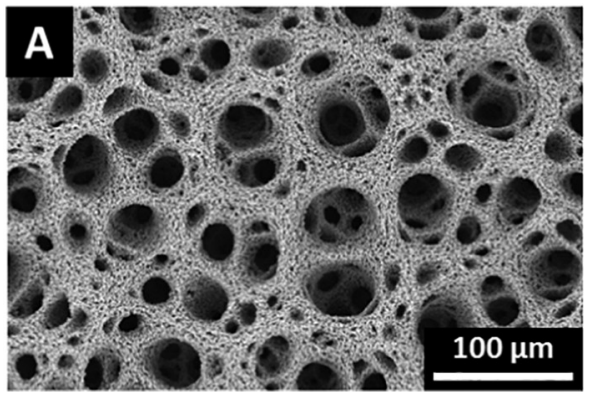

while this linearity was clearly broken for the PG surfaces (Fig. 3). This confirmed the visual difference observed by SEM between MG and PG surfaces. Higher current density made the gold layer develop a 3-dimensional porous structure but did not considerably increase the surface roughness.

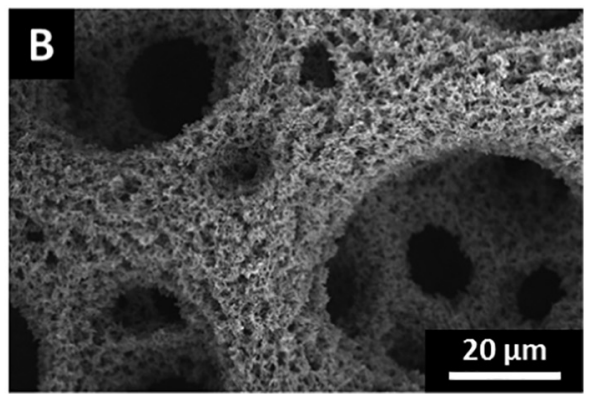

Fig. 2. SEM imaging of the porous gold (PG) electrodes. 
Table 1

Spatial arithmetical mean height $\left(S_{a}\right)$ and electrochemically active surface area $\left(A_{e}\right)$ as a function of the current densities used to perform gold electrodeposition ( $J_{\text {depositing}}$ ).

\begin{tabular}{lllll}
\hline Anode & $J_{\text {depositing }}\left(\mathrm{A} \cdot \mathrm{m}^{-2}\right)$ & $\mathrm{S}_{\mathrm{a}}(\mu \mathrm{m})$ & Roughness morphology & $\mathrm{A}_{\mathrm{e}}\left(\mathrm{cm}^{2}\right)$ \\
\hline NG & - & 0.0045 & None & 1.0 \\
MG-1 & 0.35 & 0.5 & Fir-shaped nano-dendrites & 8.9 \\
MG-2 & 0.69 & 1.7 & Fir-shaped nano-dendrites & 18.2 \\
MG-3 & 1.39 & 4.6 & Micro-craters & 36.8 \\
MG-4 & 2.08 & 6.7 & Micro-craters & 40.7 \\
PG & 5.0 & 7.6 & Porous 3D layer & - \\
\hline
\end{tabular}

\subsection{Electrode topography of micro-roughened micro-pillar arrays ( $\mu P-M G)$}

The micro-pillar arrays with smooth surfaces implemented in a previous work [34] were used again here and, in addition, the walls were roughened by gold electrodeposition at 3 different current densities (Table 1).

The rough surface structure was not uniform along the micro-pillars. The top parts of the pillars were very notably roughened, whereas the bases presented low gold deposition. It was not possible to determine roughness parameters on such structures and the surface characterization consequently consisted of an extended visual description based on SEM imaging (Table 2). At the bottom of $\mu \mathrm{P}-\mathrm{MG}-1$, the surface was slightly modified, with roughness evaluated visually at under $1 \mu \mathrm{m}$, whereas on $\mu \mathrm{P}-\mathrm{MG}-2$ and 3 , the bottom roughness was greater, reaching a few micrometres, but did not present any three-dimensional organization. Going up along the pillars, the roughness increased to reach a maximum on the top.

The deposit was thickest on the top edges of the pillars and three different deposition patterns could be distinguished (Fig. 4). On the $\mu \mathrm{P}-\mathrm{MG}$-1 surfaces, obtained with the lower electrodeposition current densities, the deposit presented a thickness of under $10 \mu \mathrm{m}$ (Fig. 4A and B). The initiation of a porous structure could be guessed but remained low and mainly composed of $10-\mu$ m wide craters. In contrast, the $\mu \mathrm{P}-\mathrm{MG}-2$ surface, which was roughened at higher current density, showed a 20 - to $30-\mu \mathrm{m}$ thick deposit consisting of a loose porous structure with pore size around $10 \mu \mathrm{m}$ (Fig. 4C). This micro-porous surface extended 50 to $100 \mu \mathrm{m}$ down the pillars, decreasing gradually. The $\mu \mathrm{P}-\mathrm{MG}-3$ surface, treated at the highest current density, displayed surface morphology similar to that of $\mu \mathrm{P}$ MG-2 but with a tighter porous structure (Fig. 4D). The total deposit height was similar but the pore size and the void degree were clearly smaller.

The electrochemically active surface area $\left(A_{e}\right.$, Table 2$)$ was consistent with the SEM images. The loose porous structure of the $\mu \mathrm{P}$ MG-2 electrode resulted in the highest active surface area, of $98 \mathrm{~cm}^{2}$. The active surface area was slightly lower for $\mu \mathrm{P}-\mathrm{MG}-3$ $\left(89 \mathrm{~cm}^{2}\right)$, which is consistent with the tight porosity observed by

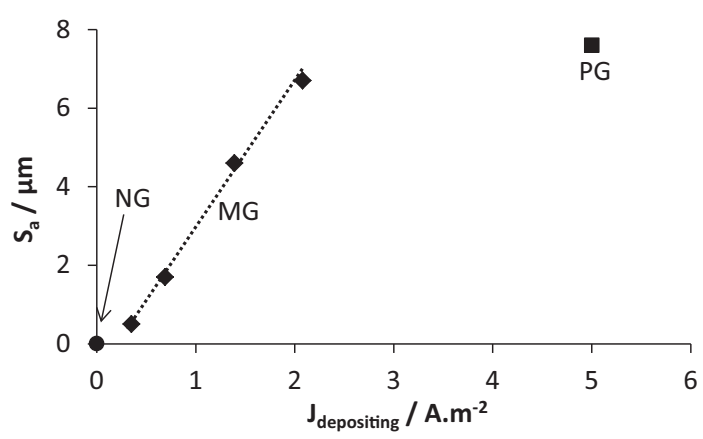

Fig. 3. Spatial arithmetical mean height $\left(S_{a}\right)$ as a function of the current density used during gold electrodeposition (Jdepositing) for the NG, MG and PG surfaces.
SEM. The two $\mu \mathrm{P}-\mathrm{MG}-1$ electrodes gave a fairly reproducible $\mathrm{A}_{\mathrm{e}}$ of 48 and $53 \mathrm{~cm}^{2}$, respectively. In comparison, the same micro-pillar networks, when implemented with a nano-rough surface of $4.5 \mathrm{~nm}$ in a previous work [34], led to considerably lower $A_{e}$ of $3.26 \mathrm{~cm}^{2}$. The roughening technique used here was efficient in increasing the electrochemically active surface area, ensuring multiplicative factors of 15 to 30 .

\subsection{Effect of micro-roughness on electroactivity establishment and biofilm growth}

The four nano-rough (NG) electrodes, used as controls, showed reproducible values (Table 3$)$ of starting time $(2.6 \pm 0.3 \mathrm{~d})$ and $J_{\max }\left(2.1 \pm 0.5 \mathrm{~A} \cdot \mathrm{m}^{-2}\right.$ on 3 values $)$. The $\mathrm{J}_{\max }$ values were consistent with the average value of $2.5 \pm 2.0 \mathrm{~A} \cdot \mathrm{m}^{-2}$ obtained in a previous study performed with 7 similar NG electrodes [34]. Here the experimental deviation was the most pronounced on the rate of increase of current density $\left(r_{i}\right)$, which ranged from 0.42 to 1.8 $A \cdot m^{-2} \cdot d^{-1}$. The large experimental deviation already observed with NG electrodes has been explained by the poor reproducibility of the surface area colonization ratio. Here, epifluorescence imaging performed after 15 days of polarization, when the current had fallen to zero, showed a similar situation. NG electrode surfaces mainly displayed isolated cells and isolated micro-colonies of different sizes, as described previously [34]. The biofilms appeared at an early stage of formation, with micro-colonies, which started to form larger patches at a few places. The NG electrodes consequently showed scattered values of biofilm coverage ratios, ranging from 26 to $57 \%$.

The starting times of the eight MG electrodes (Table 3 ) were clearly shorter $(1.6 \pm 0.1 \mathrm{~d})$ than those of the NG electrodes. The presence of micro-roughness reduced the starting time by around 1 day with respect to that recorded with the NG electrodes. As observed on the clean surfaces (Fig. 1), increased surface roughness created asperities of the size of Geobacter cells or larger, thus offering a larger contact area for bacteria to adhere to. In contrast, the lack of anchoring points on the NG surface was detrimental to bacterial adhesion and delayed the current production.

The MG electrodes showed current increase rates between 8 and 12 times higher than the NG electrodes, with $r_{i}$ values of 3.8 to 7.6 $\mathrm{A} \cdot \mathrm{m}^{-2} \cdot \mathrm{d}^{-1}$ obtained between days 1.5 and 3 (Fig. 5A). The current increase rates rose with the micro-roughness. The roughness and, probably, the presence of cavities tens of microns wide, accelerated biofilm formation.

The maximum current densities $\left(\mathrm{J}_{\max }\right)$ recorded with the MG electrodes, ranging from 5.6 to $14.0 \mathrm{~A} \cdot \mathrm{m}^{-2}$, were significantly higher than those of the NG electrodes $\left(2.1 \pm 0.5 \mathrm{~A} \cdot \mathrm{m}^{-2}\right.$ on average). Actually, after day 3.5, the current continued to increase slowly in run $\# 1$, while it tended to stabilize in run $\# 2$, which was disturbed by an accidental ingress of air into the gas supply network. The $J_{\max }$ values from run \#2 were consequently underestimated (Table 3). In spite of this technical issue, all the records showed that the MG electrodes produced considerably higher current than the NG electrodes, with a multiplication factor of 2.7 to 6.7 . The presence of micro-roughness clearly enhanced the current production.

The $J_{\max }$ values increased linearly with $\mathrm{S}_{\mathrm{a}}$ parameter values from 0.5 to $6.7 \mu \mathrm{m}$, with a slope of $0.80 \mathrm{~A} \cdot \mathrm{m}^{-2} \cdot \mu \mathrm{m}^{-1}$ (Fig. 6). Only the $J_{\max }$ values obtained from run \#1 were used for this correlation (Table 3). Nevertheless, even though the values from run \#2 were underestimated, they followed the same linear relationship with respect to $S_{a}$, with a slope of $0.85 \mathrm{~A} \cdot \mathrm{m}^{-2} \cdot \mu \mathrm{m}^{-1}$ (Fig. S1 in Supplementary data). This linear relationship was not valid for the NG electrodes, which showed that the presence of micro-roughness caused an actual jump in the current produced. 
Table 2

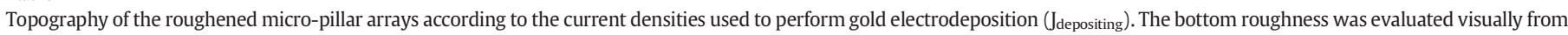

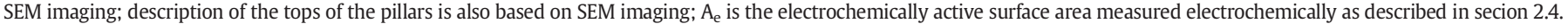

\begin{tabular}{|c|c|c|c|c|}
\hline & $J_{\text {depositing }}\left(A \cdot m^{-2}\right)$ & Bottom roughness $(\mu \mathrm{m})$ & Aspect of the surface of the top of pillars & $A_{e}\left(\mathrm{~cm}^{2}\right)$ \\
\hline$\mu \mathrm{P}-\mathrm{MG}-1$ & 0.8 & $\approx 1$ & 5-10 $\mu \mathrm{m}$ cavities & 48 \\
\hline PP-MG-1 (duplicate) & 0.8 & $\approx 1$ & 5-10 $\mu \mathrm{m}$ cavities & 53 \\
\hline$\mu \mathrm{P}-\mathrm{MG}-2$ & 1.5 & $3-4$ & $\begin{array}{l}\text { Loose porous structure } \\
30 \mu \mathrm{m} \text { thick with } 10 \mu \mathrm{m} \text { pores }\end{array}$ & 98 \\
\hline$\mu \mathrm{P}-\mathrm{MG}-3$ & 2.1 & $3-4$ & $\begin{array}{l}\text { Tight porous structure } \\
30 \mu \mathrm{m} \text { thick with } 5 \mu \mathrm{m} \text { pores }\end{array}$ & 89 \\
\hline
\end{tabular}

Cyclic voltammograms were performed after the electrodes reached $\mathrm{J}_{\max }$, on day 6 . For comparison the theoretical curve, corresponding to the Nernst-Michaelis-Menten kinetics [41,42], was added:

$J=J_{\max } \frac{1}{1+\exp \left(-\frac{F}{R T}\left(E-E_{K}\right)\right)}$

where $F$ is the Faraday constant $\left(96,485 C\right.$ per mole $\left.\mathrm{e}^{-}\right), R$ is the gas constant $\left(8.3145 \mathrm{~J} \mathrm{~mol}^{-1} \mathrm{~K}^{-1}\right), T$ is the temperature $(303 \mathrm{~K}), E$ is the applied potential $(\mathrm{V})$ and $E_{K}$ is the value of the potential extracted from the experimental curves at which $J=J_{\max } / 2$.

Fig. 5B shows that all the electrodes were efficient at oxidizing acetate from low potentials, with kinetics not far from the Nernst kinetics. The rate of electron transfer from the bacterial cell to the gold surface was consequently not far below the rate necessary to ensure the Nernst equilibrium at the electrode surface. The normalized presentation of all the CV curves in the form of $\mathrm{J} / \mathrm{J}_{\max }$ used in Fig. $5 \mathrm{~B}$ points out that the rougher electrodes tended to move the $\mathrm{CV}$ away from the theoretical Nernst curve. Increasing roughness may thus lead to slightly less efficient electron transfer kinetics.

Furthermore, Fig. 2B also shows that the NG electrode seemed to provide slightly more efficient electron transfer rates, displaying CV curves closer to the theoretical Nernst kinetics. The NG electrodes offered a large, smooth surface area on which the cell could settle completely, which probably promoted electron transfer. The NG electrodes thus provided conditions tending to have opposite effects: on the one hand, their smoothness was detrimental to cell anchoring and biofilm formation but, on the other, the large contact surface they offered to the cells might benefit the electron transfer rate. On smooth surfaces, cell adhesion is difficult and fragile but electron transfer may be promoted. Nevertheless, considering the small difference in the curves, to be fully confirmed, this speculative comment would need to be supported by a systematic study of the electrode kinetics.

The MG electrode images after 15 days of polarization showed greater colonization then the NG controls, with biofilm coverage ratios between 80 and $100 \%$ on all electrodes. The average values were 92 $\pm 7 \%, 87 \pm 4 \%, 94 \pm 3 \%$ and $91 \pm 7 \%$ on electrodes MG- 1 to 4 , respectively (Fig. 7).

Two different biofilm structures were observed. For the lowest roughness (MG-1 and MG-2), the biofilm coverage was uniform. The biofilm presented a high coverage ratio and great uniformity, while it did not look dense or thick. The biofilms on the MG-3 and MG-4 electrodes appeared denser and less uniform, showing a thickening in some areas and growing structures up to about ten micrometres high, with some mushroom-like growths. On these electrodes, craters of about $10 \mu \mathrm{m}$ were superimposed on the micrometre-sized roughness (Fig. 1). This larger scale pattern may have been responsible for the less uniform biofilm structure. The superimposed crater pattern provided a good environment for bacterial adhesion. As reported in many studies, the presence of cavities favours biofilm formation because it creates areas where shear forces are low and reduces the strength needed for primary attachment of cells to the surface [43-45]. Furthermore, bacterial communities communicate via quorum sensing systems to develop specific biofilm architectures. Biofilm shaping is a metabolic response that is triggered by the high concentration of signalling molecules. Here, the 10- $\mu$ m-sized craters may have enhanced the local accumulation of quorum sensing molecules, which favoured biofilm growth and maturation. The presence of mushroom structures may thus have been the result of the more rapid biofilm maturation promoted inside the craters.
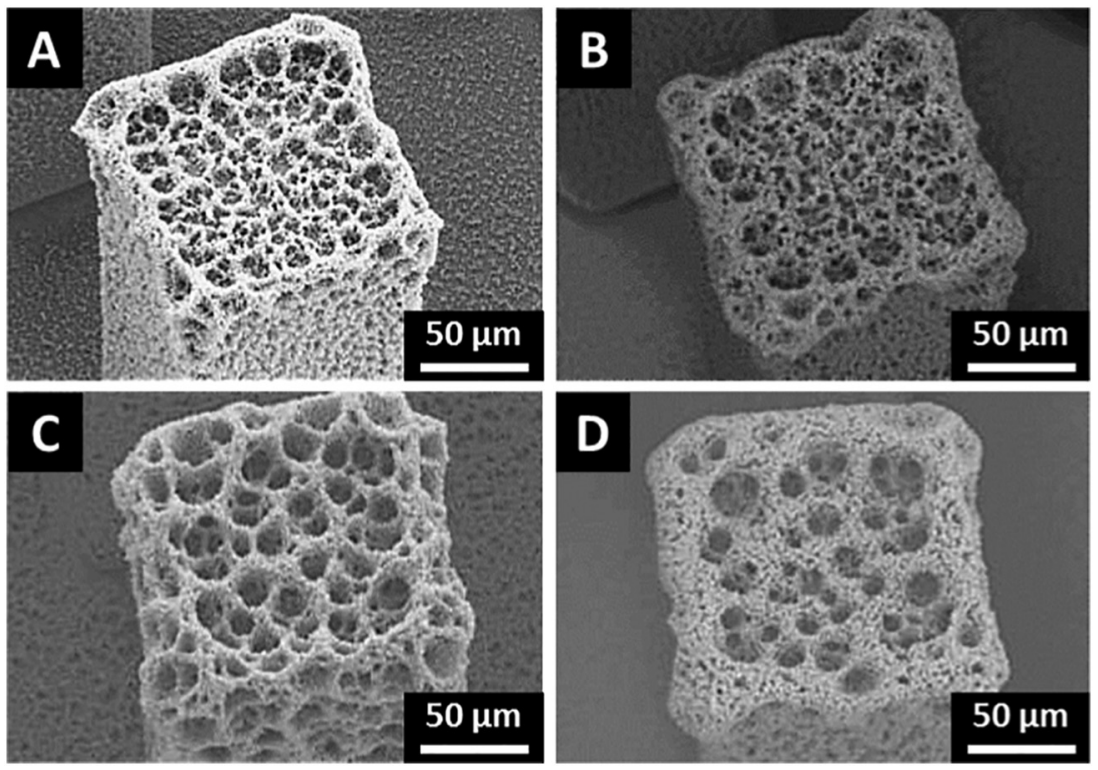

Fig. 4. SEM imaging of the top of the $\mu \mathrm{P}-\mathrm{MG}$ surfaces: (A and B) $\mu \mathrm{P}-\mathrm{MG}-1$ duplicates; C) $\mu \mathrm{P}-\mathrm{MG}-2$; D) $\mu \mathrm{P}-\mathrm{MG}-3$. 
Table 3

Electrochemical parameters measured on the chronoamperograms as described in Section 2.2: maximum current density $\left(\mathrm{J}_{\max }, \mathrm{A} \cdot \mathrm{m}^{-2}\right)$, the starting time $\left(\mathrm{t}_{\text {start }}\right.$, days $)$, defined as the time required for the current to reach $10 \%$ of $J_{\max }$, and the current density increase rate $\left(r_{i}, A \cdot m^{-2} \cdot d^{-1}\right)$, calculated as the average value of the slope of the current density vs. time over 1 day around the inflection point of the curve.

\begin{tabular}{llll}
\hline Surface & Starting time, $\mathrm{t}_{\text {start }}(\mathrm{d})$ & Increase rate, $\mathrm{r}_{\mathrm{i}}\left(\mathrm{A} \cdot \mathrm{m}^{-2} \cdot \mathrm{d}^{-1}\right)$ & $\mathrm{J}_{\max }\left(\mathrm{A} \cdot \mathrm{m}^{-2}\right)$ \\
\hline NG & 2.4 & 0.52 & 1.7 \\
& 2.8 & 0.42 & $1.4^{\mathrm{a}}$ \\
& 2.4 & 1.8 & 2.1 \\
$\mathrm{MG}-1$ & 2.9 & 1.4 & 2.6 \\
& 1.5 & 3.8 & 9.0 \\
$\mathrm{MG}-2$ & 1.7 & 3.9 & $5.6^{\mathrm{a}}$ \\
& 1.6 & 4.6 & 10.3 \\
$\mathrm{MG}-3$ & 1.6 & 4.6 & $7.0^{\mathrm{a}}$ \\
& 1.6 & 6.2 & 13.2 \\
$\mathrm{MG}-4$ & 1.5 & 5.0 & $8.6^{\mathrm{a}}$ \\
& 1.8 & 7.6 & 14.0 \\
PG & 2.7 & 7.0 & $11.3^{\mathrm{a}}$ \\
& 2.7 & 7.6 & 15.9 \\
$\mu \mathrm{P}-\mathrm{MG}-1$ & 0.9 & 7.9 & 14.7 \\
$\mu \mathrm{P}-\mathrm{MG}-1$ & 0.9 & 7.3 & 13.8 \\
$\mu \mathrm{P}-\mathrm{MG}-2$ & 1.0 & 1.4 & 5.9 \\
$\mu \mathrm{P}-\mathrm{MG}-3$ & 0.9 & 1.4 & 5.8 \\
\hline
\end{tabular}

a The values of $J_{\max }$ from run \#2 (see Section 2.2) were underestimated because of air ingress into the gas network supply.

\subsection{Effect of porosity on electroactivity establishment and biofilm growth}

The porous gold electrodes (PG) showed reproducible behaviour (Fig. S2A in Supplementary Data) for the phase of current establishment. Cyclic voltammetries performed at day 5 , when the bioanodes were close to reaching maximum current production, confirmed the
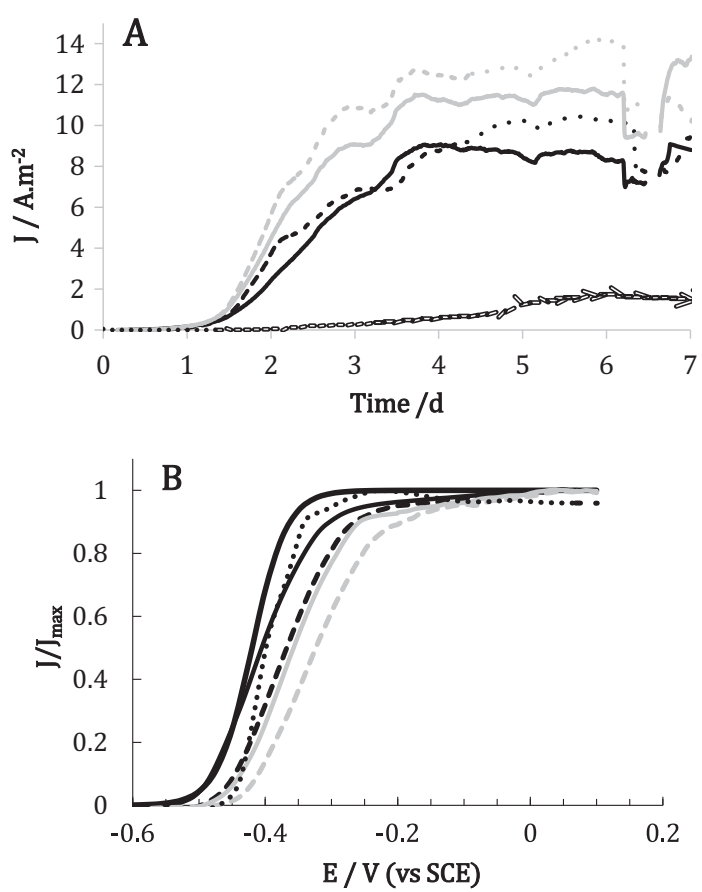

Fig. 5. Nano-rough (NG) and 4 micro-rough (MG) gold electrodes (run \#1). (A) Chronoamperograms at $0.1 \mathrm{~V} / \mathrm{SCE},(\mathrm{B})$ voltammograms recorded at $1 \mathrm{mV} \cdot \mathrm{s}^{-1}$ at day 6. Black dotted line: NG; black continuous line: $\mathrm{MG}-1$; black dashed line: $\mathrm{MG}-2$; grey continuous line: MG-3; grey dashed line: MG-4; the continuous double line is theoretical Nernst kinetics (Eq. (2)). It can be observed on the chronoamperograms at day 6 that $\mathrm{CV}$ recording can disturb the biofilm formation, as is particularly noticeable for MG-3 and MG-4.

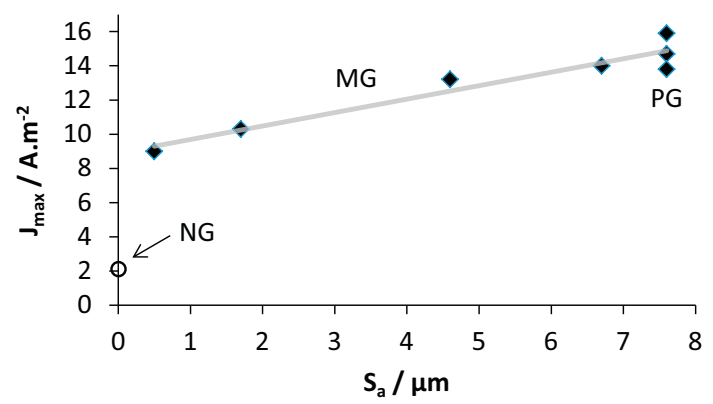

Fig. 6. Maximum current densities $\left(\mathrm{J}_{\max }\right.$ ) reached during polarization at $0.1 \mathrm{~V} / \mathrm{SCE}$ vs. the spatial arithmetical mean height $\left(\mathrm{S}_{\mathrm{a}}\right)$ for the nano-rough (NG), micro-rough (MG) and porous (PG) gold electrodes.

great reproducibility of the three bioanodes (Fig. S2B in Supplementary Data) and also their excellent kinetics, close to the theoretical NernstMichaelis-Menten kinetics.

The PG electrodes showed $r_{i}$ and $J_{\max }$ values comparable to those of the MG-4 electrodes (Table 3 ). The rates of current density increase were identical to those of the MG-4 electrodes, the maximum current densities were only slightly improved and the start-up times were longer for the porous electrodes. The thick porous layer was consequently not markedly more efficient than micro-roughness. Starting times were longer and maximum current densities were only slightly improved.

The spatial arithmetic mean height $\left(S_{a}\right)$ was $6.7 \mu \mathrm{m}$ for the MG-4 electrodes and $7.6 \mu \mathrm{m}$ for the porous electrodes (Table 1). The linear relationship between $\mathrm{J}_{\max }$ and $\mathrm{S}_{\mathrm{a}}$ observed for the MG electrodes was fully validated with the PG electrodes (Fig. 6). Actually, the 100- $\mu$ m thick porous structure behaved like a 2-dimensional micro-rough surface. This conclusion is consistent with pore clogging, which was observed on most of the electrode surface area.

The reactors were stopped at day 18 to image the biofilms. Epifluorescence microscopy showed a dense, uniform biofilm, with a thickness of around 20-30 $\mu \mathrm{m}$. In some areas, the biofilm was punctured above the pores (Fig. 8A) but, in most spots, it completely covered the pores (Fig. 8B). This resulted in an almost uniform biofilm with a bumpy appearance as seen on the 3-dimensional reconstruction (Fig. 8C).

SEM imaging of the third PG electrode confirmed that the biofilm covered the majority of the surface area with only some rare spots where unclogged pores appeared. SEM imaging also showed that the walls of the open pores were often lined with a continuous biofilm going as deep as could be observed (Fig. 9A). During the drying process, in a few spots, a layer around $50 \mu \mathrm{m}$ thick of the porous deposited gold cracked and pulled away. This allowed observations of pores in depth, below the top surface. Hence, it was observed that the pores clogged by the $20-\mu \mathrm{m}$ thick biofilm over their opening had been deeply colonized, similarly to the unclogged pores (Fig. 9B). A biofilm around 5 to 10 cells thick was observed on most of the pore walls. This internal colonization of the pores could be observed as deep as the porous structure was cracked, i.e. around $50 \mu \mathrm{m}$. Finally, when zooming in at the cell scale, we observed gold rods of tens of nanometres tightly interdigitated with Geobacter cells (Fig. 9C), which suggests that the small scale roughness was fully suitable for entrapping cells. The gold deposit made here appeared highly suitable for bacterial colonization, leading to tight interdigitation between gold structures and cells.

\subsection{Effect of roughened micro-pillars on electroactivity establishment and biofilm growth}

One way to avoid clogging of a porous structure by a biofilm covering the top was to design larger pores or a structure with more space 

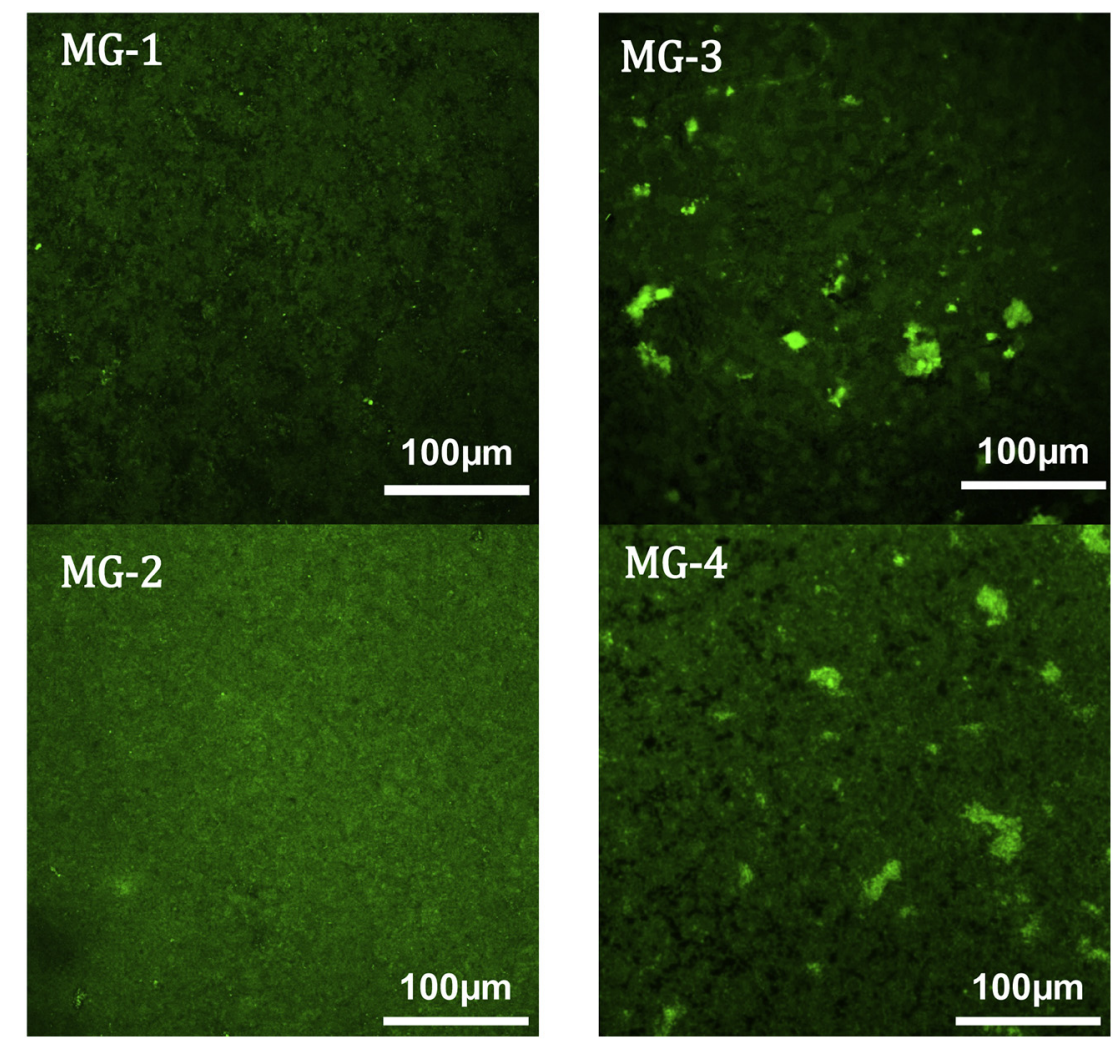

Fig. 7. Epifluorescence microscopic imaging of Geobacter sulfurreducens biofilms formed on MG-1 to MG-4 electrodes after 15 days of polarization at 0.1 V/SCE.

between protuberances. To this end, we re-used the micro-pillar arrays implemented in a previous work [34], with a pillar spacing of $200 \mu \mathrm{m}$.

The four electrodes ( $\mu \mathrm{PG}-\mathrm{MG}$ ) exhibited similar chronoamperograms (Fig. S3 in Supplementary Data). The two $\mu$ PG-MG-1 electrodes gave identical chronoamperogram characteristics (Table 3). The $\mu \mathrm{PG}-\mathrm{MG}-2$ electrode gave slightly higher $\mathrm{r}_{\mathrm{i}}$ and $\mathrm{J}_{\max }$ values, which suggested that the thicker and looser porous structure observed on the top of the $\mu \mathrm{PG}-\mathrm{MG}-2$ surface was the most suitable for the development of electroactive biofilm. Nevertheless, close $\mathrm{J}_{\max }$ values were obtained, with only around $30 \%$ variations (Table 3 ), while their electrochemically active surface area varied by a factor of two (Table 2). The current produced by the bioanodes was thus slightly impacted by the electrochemically active surface area.

Cyclic voltammograms recorded at day 7, when the electrodes were not far from producing the maximum current density, confirmed the fair reproducibility observed on the electrochemical characteristics (Fig. S3B in Supplementary Data).

At the end of the experiments, electrode colonization was characterized by epifluorescence microscopy (Fig. 10). For all the bioanodes, the bottom of the electrode structure displayed faint fluorescence, indicating a thin biofilm. In contrast, the top of the pillars looked well colonized by a thicker biofilm. On the $\mu \mathrm{P}-\mathrm{MG}-1$ electrodes, the colonization on top of the pillars was uniform with a fully covering biofilm (Fig. 10A). On $\mu \mathrm{P}-\mathrm{MG}-2$ and -3 , the biofilm did not clog the pores and had penetrated the porous structure, at least for a few micrometres (it was not possible to see deeper into the porous structures). The microscopic observation revealed a clear difference in biofilm formation: well-formed biofilms on the top and poor colonization at the bottom.

The previous study [34], which implemented the same micro-pillar arrays but with a nano-rough surface $\left(R_{a}=4.5 \mathrm{~nm}\right)$, led to current densities of 5.9 and $6.3 \mathrm{~A} \cdot \mathrm{m}^{-2}$ related to the projected surface area. Here, roughening the pillar surface led to a very modest gain, of 1.3 -fold at most.

In comparison, here, in flat configuration, the MG surfaces obtained by roughening the same NG surface increased the $\mathrm{J}_{\max }$ by a factor of 2.7 to 6.7 (Table 3). Roughening greatly impacted the current produced by the flat bioanodes, but it lost much of its interest in the case of the micro-pillar arrays.

The biofilm structure described above suggests an explanation for this difference between flat surfaces and micro-pillar arrays.
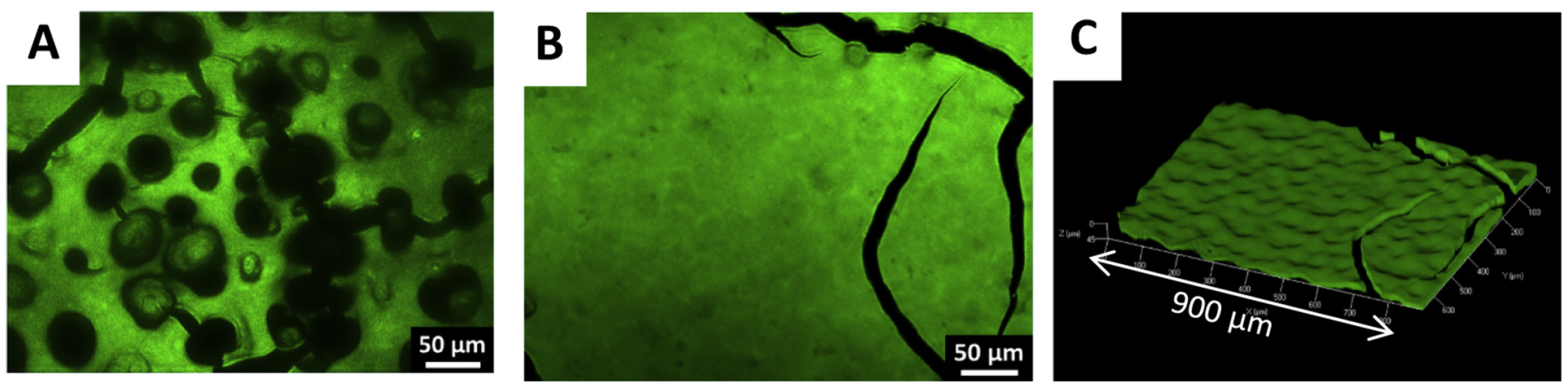

Fig. 8. Epifluorescence imaging of a PG electrode after 18 days of polarization at $0.1 \mathrm{~V} / \mathrm{SCE}$; A) and B) top view, C) 3D reconstruction. 

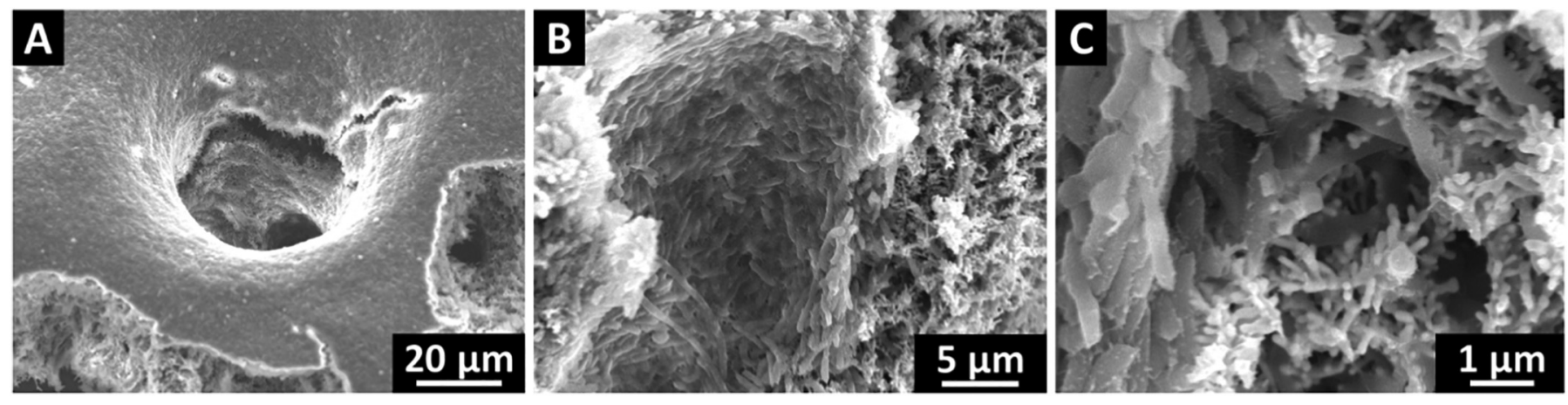

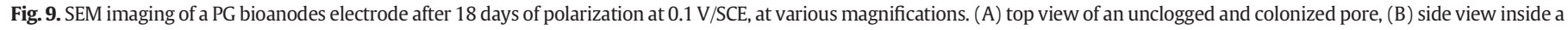
pore that was under a cracked layer, and (C) close up of Geobacter sulfurreducens cells entrapped in the gold surface.

The biofilms were well-developed on the top of the micro-pillars, while the bottom was poorly colonized. It can consequently be assumed that the current was mainly produced by the fully developed biofilm on top of the micro-pillars (Fig. 10). Only the top part of the micro-pillar array was efficient.

An elementary quantification supports this hypothesis. On flat micro-rough surfaces, the highest current densities recorded were of the order of $14 \mathrm{~A} \cdot \mathrm{m}^{-2}$ (Table 3 ). The highest current density recorded on roughened micro-pillars was roughly of the order of $8 \mathrm{~A} \cdot \mathrm{m}^{-2}$. Assuming that the surface of the roughened micropillars produces the same current density as the roughened flat surface, $0.57 \mathrm{~cm}^{2}$ of micro-pillar surface area would be sufficient to obtain $8 \mathrm{~A} \cdot \mathrm{m}^{-2}$. A micro-pillar array of $1 \mathrm{~cm}^{2}$ projected surface area corresponds to a geometric surface area of $3.18 \mathrm{~cm}^{2}(500 \mu \mathrm{m}$ height, $100 \mu \mathrm{m}$ wide, $200 \mu \mathrm{m}$ spacing). This means that around $18 \%$ of the surface area of the micro-pillar array working at $14 \mathrm{~A} \cdot \mathrm{m}^{-2}$ would be sufficient to produce $8 \mathrm{~A} \cdot \mathrm{m}^{-2}$. This surface ratio corresponds to the top of the micro-pillars and around 100 $\mu \mathrm{m}$ of their upper sides. Only the upper part of the micro-pillar array was working.

This hypothesis is reinforced by the theoretical approach developed previously [34], which showed strong mass transfer limitation of the buffer species $\mathrm{HCO}_{3}^{-}$inside a pillar array. Acetate oxidation causes acidification in the vicinity of the bioanode surface:

$$
\mathrm{CH}_{3} \mathrm{COO}^{-}+2 \mathrm{H}_{2} \mathrm{O} \Longleftrightarrow 2 \mathrm{CO}_{2}+7 \mathrm{H}^{+}+8 \mathrm{e}^{-}
$$

which has been shown to be heavily detrimental to electroactive biofilms [46-48]. According to the equations developed previously, the modified Damköhler number $\left(\mathrm{Da}_{\text {mod }}\right)$ relative to $\mathrm{HCO}_{3}^{-}$is:

$\mathrm{Da}_{\text {mod }}=\frac{J_{l o c} \delta}{n F \quad D C^{0}}$

where $J_{l o c}\left(\mathrm{~A} \cdot \mathrm{m}^{-2}\right)$ is the local current density, i.e. the current density expressed with respect to the geometric surface area of the pillars, $\delta\left(50010^{-6} \mathrm{~m}\right)$ is the micro-pillar height, $\mathrm{n}$ is the number of electrons produced per molecule of $\mathrm{HCO}_{3}^{-}$consumed, and $F$ (96 $\left.485 \mathrm{C} \cdot \mathrm{mol}^{-1}\right)$ is the Faraday constant, $D\left(1.1810-9 \mathrm{~m}^{2} . \mathrm{s}^{-1}\right.$ [49]) is the diffusion coefficient of $\mathrm{HCO}_{3}$, and $\mathrm{C}^{0}\left(\mathrm{~mol} \cdot \mathrm{m}^{-3}\right)$ is the concentration at the top of the micro-pillar array.

The value of $n$ was taken as $8 / 7$ because, for 8 electrons produced, $7 \mathrm{~mol}$ of $\mathrm{HCO}_{3}^{-}$are consumed to neutralize the 7 protons produced (Reaction 3). The concentration of $\mathrm{HCO}_{3}^{-}$was $29.6 \mathrm{mM}$ in the bulk of the solution and $C^{0}$ was calculated by assuming a diffusion layer of
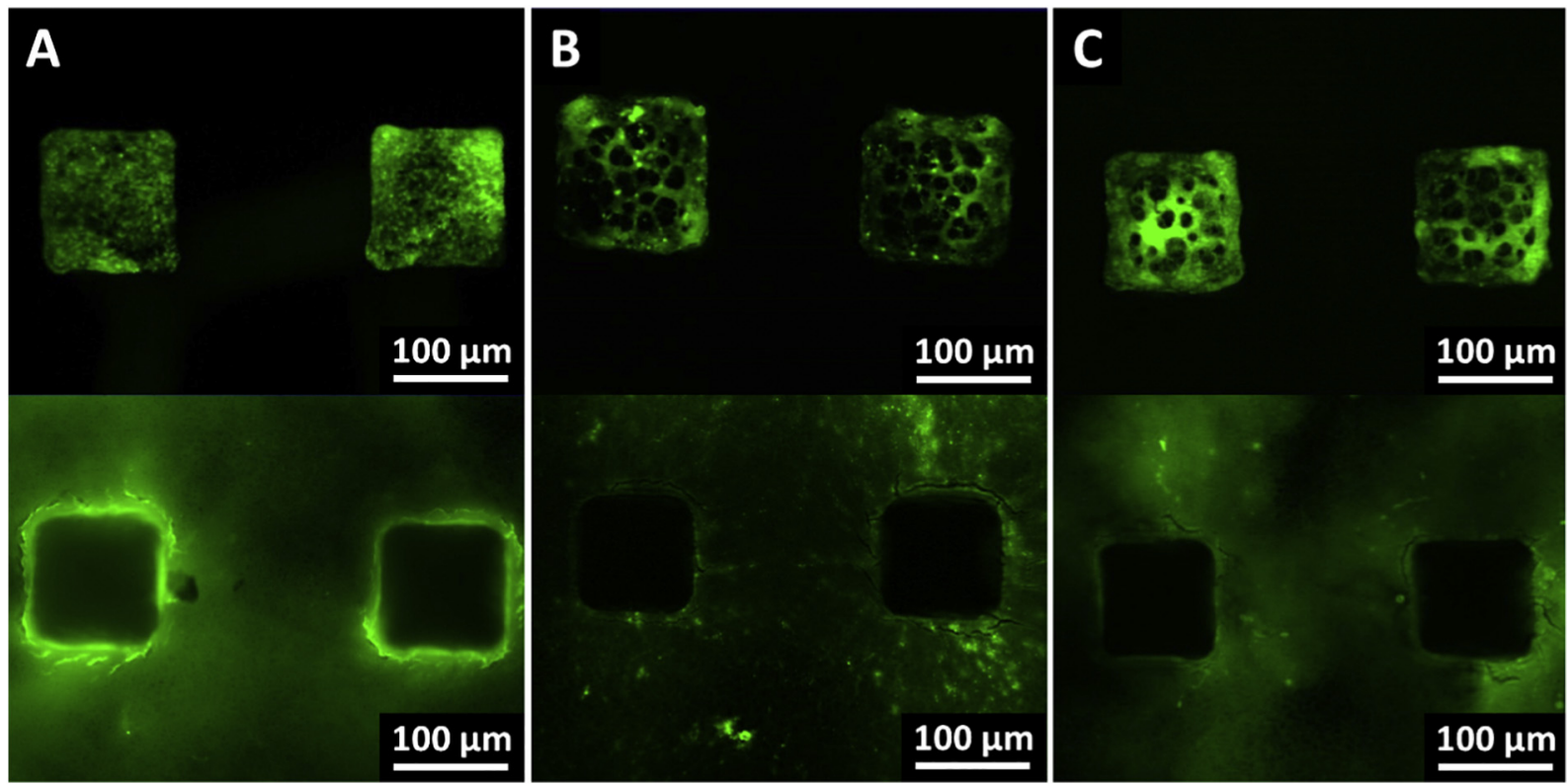

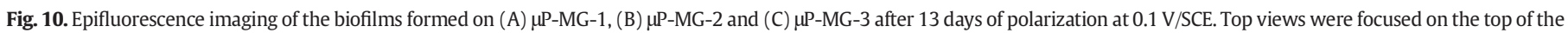
micro-pillars and bottom views on the base of the electrode structure. 
$100 \mu \mathrm{m}$ above the top of the micro-pillar array (Fig. 9), which is a common value for an electrochemical process in quiescent solution. $\mathrm{Da}_{\bmod }$ expresses the rate of consumption by the electrochemical reaction with respect to the maximum diffusion rate along the micro-pillar. It must be corrected by a geometric ratio $(\zeta)$ :

$\zeta=\frac{l_{a} \delta}{S}$

where $l_{a}(\mathrm{~m})$ is the electrochemically active length in the section of the elementary unit and $S\left(\mathrm{~m}^{2}\right)$ is the section of the elementary unit that is free for diffusion (Scheme 1). $\zeta$ expresses the overall electrochemically active area in the elementary unit with respect to the section available for diffusion.

It was assumed that, locally, the surface of the roughened micropillars produced the same current density as the roughened flat surface, so $J_{l o c}=14 \mathrm{~A} \cdot \mathrm{m}^{-2}$. In this condition, $\zeta \mathrm{Da}_{\bmod }$ is equal to 5.7 , showing that the rate of consumption by the electrochemical reaction is considerably higher than the maximum diffusion rate of the buffering species. With this theoretical approach, the $\mathrm{HCO}_{3}^{-}$concentration and the $\mathrm{pH}$ profiles along the micro-pillars can be calculated (Fig. 11, continuous lines). The model predicts that $\mathrm{HCO}_{3}^{-}$is consumed very early in the upper part of the micro-pillar structure, so the $\mathrm{pH}$ sinks to very low values. The order of magnitude of the penetration depth of $\mathrm{HCO}_{3}^{-}$is around $60 \mu \mathrm{m}$. This value is consistent with the elementary calculation made above, which indicated that $100 \mu \mathrm{m}$ of pillar height was sufficient to ensure the current density of $8 \mathrm{~A} \cdot \mathrm{m}^{-2}$. Actually, the penetration depth of the $\mathrm{HCO}_{3}^{-}$should be enhanced by the migration flux, which has been neglected in the reaction-diffusion approach used to establish the Damköhler number.

For comparison, the calculation made in the previous work [34] for nano-rough micro-pillars that produced $6.1 \mathrm{~A} \cdot \mathrm{m}^{-2}$ with $\mathrm{J}_{\text {loc }}$ of 1.87 $\mathrm{A} \cdot \mathrm{m}^{-2}$ is also plotted in Fig. 11 (dashed lines). In this case, the diffusion of $\mathrm{HCO}_{3}^{-}$along the micro-pillar also showed significant limitation, but it reached the bottom of the structure. This confirmed that the fall of $\mathrm{HCO}_{3}^{-}$ concentration in the upper part of the micro-pillar structure was due to the increase of the local reaction rate $\left(\mathrm{J}_{\text {loc }}\right)$ because of the roughened structure.

In conclusion, the three approaches:

- observation of the very different levels of biofilm development at the top and bottom of the micro-pillar structure,

- comparison with the current density produced by flat micro-rough surfaces,

- theoretical modelling of $\mathrm{HCO}_{3}^{-}$transport,

converge to show that roughening the micro-pillar surface resulted in high efficiency of the upper part, which precluded the exploitation of lower area of the micro-pillars. The high local current density achieved on the upper part of the micro-pillars consumed the whole flux of the buffering species, which could consequently not mitigate the

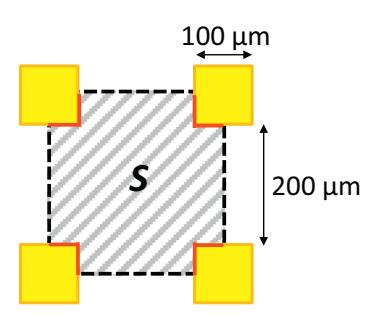

A- Top view

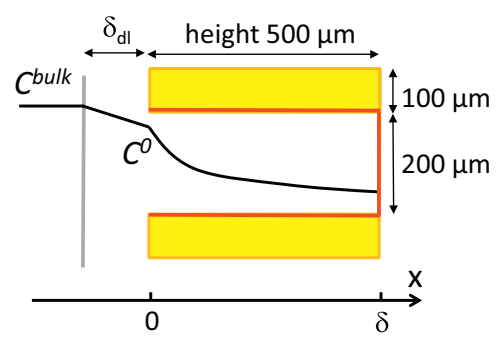

B- Side view
Scheme 1. Elementary unit of a micro-pillar array. A) top view; B) the side view. $\mathrm{S}$ is the section free for diffusion, $\delta_{\mathrm{dl}}$ is the diffusion layer above the micro-pillar array; on the side view the concentration profile of a species consumed by the electrochemical reaction is schematized.
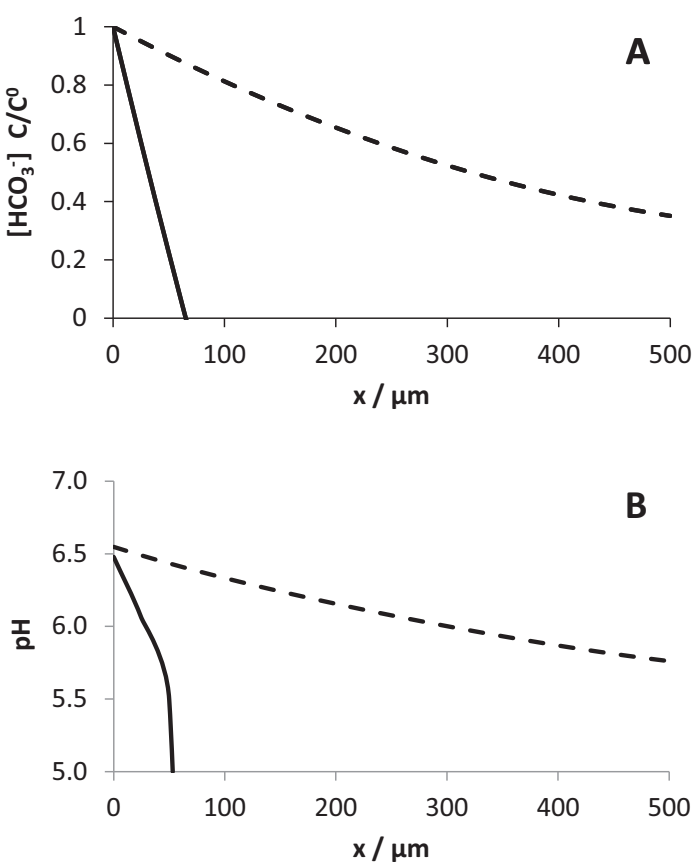

Fig. 11. Theoretical (A) $\mathrm{HCO}_{3}^{-}$concentration in dimensionless form $\left(C / C^{0}\right)$ and $(B) p H$ profile as a function of the distance (x) from the top of the pillars (see Scheme 1). Continuous lines correspond to roughened micro-pillars producing $8 \mathrm{~A} \cdot \mathrm{m}^{-2}$ with $\mathrm{J}_{\mathrm{loc}}$ of $14 \mathrm{~A} \cdot \mathrm{m}^{-2}$ (this work); dashed lines correspond to non-roughened micro-pillars producing $6.1 \mathrm{~A} \cdot \mathrm{m}^{-2}$ with $\mathrm{J}_{\text {loc }}$ of $1.87 \mathrm{~A} \cdot \mathrm{m}^{-2}$ [34].

acidification of the lower part of the array. This resulted in severe acidification of the lower part of the micro-structure (Scheme 2).

\section{Discussion and further research directions}

A correlation was sought by expressing the maximum current density with respect to the electrochemically active surface area $\left(A_{e}\right)$. In this form, the current density produced by the micro-rough electrodes (MG) was lower than that produced by the nano-rough electrodes (NG), and the current density decreased as $S_{a}$ increased (Table 4). When the roughness increased, the increased electrochemically active surface area was less and less accessible for microbial settlement. Furthermore, the current density related to $A_{e}$ was even smaller for the roughened micro-pillar arrays than for the MG electrodes.

This raises the question of the most appropriate way to measure the active surface area available for biofilm settlement. Here, expressing the current density with respect to $A_{e}$ gave considerably higher values for the NG electrodes while, in practice, the NG electrodes produced smaller currents. The electrochemical technique used here to measure

$$
\begin{array}{cc}
\text { Upper part } & \text { Inefficient lower part } \\
J_{\text {loc }}=14 \mathrm{~A} \cdot \mathrm{m}^{-2} & \text { because of acidification }
\end{array}
$$

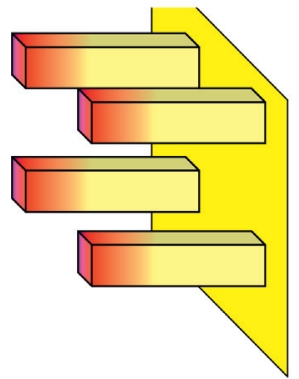

Scheme 2. Roughened micro-pillar array. The efficient upper part (red) of the micropillars causes a severe acidification of the lower part (yellow). 
$J_{\max }$ values expressed with respect to the projected surface area $\left(1 \mathrm{~cm}^{2}\right)$ or with respect to the electrochemical surface area $\left(A_{e}\right)$.

\begin{tabular}{|c|c|c|c|c|c|c|c|c|c|}
\hline & $\mathrm{NG}^{\mathrm{a}}$ & MG-1 & MG-2 & MG-3 & MG-4 & $\mu \mathrm{P}-\mathrm{MG}-1$ & $\mu \mathrm{P}-\mathrm{MG}-1$ & $\mu \mathrm{P}-\mathrm{MG}-2$ & $\mu \mathrm{P}-\mathrm{MG}-3$ \\
\hline $\mathrm{J}_{\max }\left(\mathrm{A} \cdot \mathrm{m}^{-2}\right)$ & 2.1 & 9.0 & 10.3 & 13.2 & 14.0 & 5.9 & 5.8 & 7.8 & 7.0 \\
\hline$A_{e}\left(\mathrm{~cm}^{2}\right)$ & 1.0 & 8.9 & 18.2 & 36.8 & 40.7 & 48 & 53 & 98 & 89 \\
\hline$J_{\max }$ with respect to $A_{e}\left(A \cdot m^{-2}\right)$ & 2.1 & 1.0 & 0.57 & 0.36 & 0.34 & 0.12 & 0.11 & 0.08 & 0.08 \\
\hline
\end{tabular}

a Average for the $3 \mathrm{NG}$ electrodes, standard deviation $\pm 0.5 \mathrm{~A} \cdot \mathrm{m}^{-2}$.

$A_{e}$ overestimated the surface area that could actually be reached by the microbial cells. The electrochemical measurements were based on the oxidation and reduction of the oxide layers, which involves only a few monomolecular layers on the gold surface. This measurement scale, at the Angstrom level, was much too small to assess the surface available for microbial cells, which have characteristic sizes of at least $1 \mu \mathrm{m}$. The electrochemically active surface area is a useful parameter for assessing the physical effect of the roughening technique, but it cannot be used to calculate the local current density. This surface area is overestimated with respect to the surface area that is really available for cell settlement. In the case of the micro-pillar arrays, the mass transfer limitation is superimposed and causes the current density to drop further.

The electrodepositing technique used here succeeded in producing gold deposits favouring tight bacterial colonization and ensuring efficient electron transfer with electroactive cells. The proximity of the voltammetric curves with the theoretical Nernst-Michaelis-Menten kinetics was a proof of the electron transfer efficiency that occurred between these gold surfaces and the microbial cells.

Roughness at the micrometre scale greatly increased the current density with respect to the nano-rough surface $\left(R_{a}=4.5 \mathrm{~nm}\right)$, by a factor of 2.7 to 6.7. Actually, nano-rough electrodes were not fully appropriate for biofilm formation. Difficult bacterial adhesion resulted in low and poorly reproducible biofilm coverage even after more than 12 days of polarization. Micro-roughening of the surface, from 0.5 to $6.7 \mu \mathrm{m}$, favoured bacterial adhesion and led to full biofilm formation and higher current production. The complete, uniform biofilm coverage promoted by the micro-roughness is undoubtedly a major reason for the great current enhancement.

The current density increased linearly with $\mathrm{S}_{\mathrm{a}}$. It was observed that the 10- $\mu \mathrm{m}$ micro-craters (MG-3 and MG-4) accelerated biofilm growth locally but did not increase the current density beyond the value due to the increase in $S_{a}$. It can be concluded that $S_{a}$ is a fully appropriate parameter for checking the effect of surface topography on the current density provided by electroactive biofilms. Nevertheless, the decoupling observed between the status of biofilm development and the current density shows that biofilm electroactivity is a complex process that does not correspond to the simple addition of similar contributions from individual microbial cells.

The porous layers produced current densities of up to $15.9 \mathrm{~A} \cdot \mathrm{m}^{-2}$, i.e. $14.8 \pm 1.1 \mathrm{~A} \cdot \mathrm{m}^{-2}$ on average for 3 electrodes. Nevertheless, the porous structure was far from being fully exploited because of the formation of a covering biofilm on the upper surface that clogged the porosity. As a major message, it should be kept in mind that pores several tens of micrometres in diameter were quickly clogged by the biofilm.

A similar result has already been suggested in the literature by Kipf et al., who observed that Geobacter sulfurreducens unexpectedly gave similar performance on activated carbon and graphite felt [50]. The thick biofilm formed was suggested to be an element of the explanation. Similarly, microbial anodes formed on 2-dimensional carbon cloth have been shown to perform as efficiently as those formed on porous felt, because the biofilm formed on the upper side of the carbon felt clogged the porosity of the felt electrode [51]. In this case, the operating conditions were very different, microbial anodes were formed in wastewater, fed with food waste and inoculated with biological sludge. The present study confirmed that, even in well-controlled pure culture conditions, electroactive biofilms can clog pores several tens of micrometres in diameter quite fast during their formation phase.
With respect to the basic nano-rough electrode, current density was multiplied by a factor greater than 7 when the porous layer was used. The porous structure greatly improved the current density. This improvement was directly linked to the increase in surface roughness. Porosity acted as an increase of surface roughness, i.e. through the 2-dimensional effect it induced on the upper surface, rather than through a 3-dimensional effect. In this context, $\mathrm{S}_{\mathrm{a}}$ remains the appropriate parameter to assess the effect of electrode topography on the current density produced. Moreover, the linear relationship observed with the micro-rough electrodes remained valid with the porous ones. This is a major conclusion that should be kept in mind to possibly reinterpret the impact of porosity on microbial anode performance. Actually, some current increases that have been roughly attributed to the effect of 3-dimensional porosity in the literature so far may have been due to the impact of the porosity on the upper surface roughness.

As illustrated in the introduction, the results reported in the literature on the impact of the surface micro-roughness on electroactive biofilms are diverse. The results obtained here are in line with the reports that have observed an impact of the roughness at the size of a few micrometres $[23,28,52,53]$. These studies didn't propose correlations between roughness and the produced current density. Here, taking care to modify the surface roughness, without affecting other surface parameters, revealed a significant and increasing impact of surface roughness over a wide range from 0.5 to around $8 \mu \mathrm{m}$, including the effect of porosity. This range of action is larger than reported in a study carried out with stainless steel, which observed an effect of roughness only above $2 \mu \mathrm{m}$ [23].

Protuberant micro-structures have been shown to improve the performance of microbial anodes, mainly by increasing the surface area available for biofilm growth. Gold cross-shaped micro-pillars $40 \mu \mathrm{m}$ wide and $8 \mu \mathrm{m}$ high have been shown to increase the current produced by $S$. cerevisiae 4.9 fold because they expanded the surface area to volume ratio by a factor of 4.5 [54]. The presence of $20 \mu \mathrm{m}$ high and $20 \mu \mathrm{m}$ diameter cylindrical micro-pillar arrays improved the current produced by S. marcescens 1.5 times [55]. In our previous study, $100 \mu \mathrm{m}$ wide and $500 \mu \mathrm{m}$ high micro-pillar patterning led to current densities being improved by factors of up to 8 , related to higher surface area [34].

Here, it was decided to use the same micro-pillar arrays as previously investigated, with the objective of improving the performance by roughening the pillar surfaces. The effect of roughening was not as impressive as expected. Current density values showed a modest 1.3fold gain with respect to the non-roughened micro-pillar arrays. The theoretical approach indicated that current enhancement was effective but the local high current density produced at the top of the micropillars exacerbated the mass transfer limitation. Mass transfer of the buffering species was no longer able to mitigate the acidification at the bottom of the micro-pillar array. This issue points out, once again, the crucial importance of interfacial acidification [46-48] and the importance of ion transport to mitigate it [56].

The upper part of the roughened micro-pillars was too efficient and precluded functioning of the bottom part. The theoretical approach indicated that, with the roughened surface, micro-pillars of around 60to $100-\mu \mathrm{m}$ height would be sufficient. Higher pillars could be used if the space between them was increased in order to favour mass transport. An optimum has to be found, and the simple mass transfer calculation used here provides some first basic guidelines for optimizing 
the topography of bioanodes. Furthermore, it may be favourable to decrease the micro-pillar width to a few tens of micrometres, or less if technologically possible, with the objective to induce ultramicroelectrode effect, which has been shown to positively impact the current produced by the biofilms that form around electrodes of such dimension [57].

Obviously, in the context of well-controlled conditions, promising ways to improve the interfacial performance would be to find acidophilic electroactive strains, but they remain rare and not really efficient [58]. Increasing the concentration of the buffer species by acclimating electroactive species to high buffer concentrations may be another promising way to progress on bioanode performance.

In conclusion, the present results indicate that creating surface roughness of a few micrometres is a fully appropriate way to accelerate the formation of bioanodes and to increase the current they produce in their formation phase. Progress might still be made by microstructuring the surface. In this context, the optimal topography is directly dependent on the capacity of the strain to resist acidification. A simple theoretical tool is described here to start optimizing the microdesign of bioanode surfaces.

\section{Conclusion}

Current density was increased by a factor of up to 6.7 by surface micro-roughness with respect to nano-rough surfaces. For $S_{a}$ ranging from 0.5 to $7.6 \mu \mathrm{m}$, current density increased linearly with $S_{a}$ and this relationship remained valid for porous structures. Porosity was shown to impact the bioanode by modifying the 2-dimensional surface topography here rather than through 3-dimensional colonization. Combining roughness and micro-pillars resulted in lower current density than flat roughness. This result was explained by a limitation on ion transport inside the micro-pillar arrays and a simple theoretical tool was provided to progress towards optimal surface topography.

It must be kept in mind that the conclusions drawn here concern the early formation of Geobacter sulfurreducens biofilms. The main objective was to impact the starting phase in order to accelerate the biofilm formation and the current production. These results should now be confronted with different situations: mature biofilms, biofilms of other strains and multispecies biofilms [59]. Unravelling the impact of the surface topography on the formation and performance of microbial anodes will be a long and complex task. Here, we hope to have provided the research community with a basic brick that will help to build up a sound foundation for future works.

\section{Declarations of interest}

None.

\section{Acknowledgements}

This work received the support of the French state, managed by the Agence Nationale de la Recherche (ANR), within the framework of the project Koropokkuru (ANR-14-CE05-0004).

The authors would like to acknowledge Luc Etcheverry, Fréderic Dacosta, Jean-Pierre Escafit and Vincent Loisel (Laboratoire de Génie Chimique) for their help in designing and setting up the reactors. Cécile Pouzet (Plateforme Imagerie-FR AIB) and Benjamin Erable (Laboratoire de Génie Chimique) are gratefully acknowledged for their implication in the fluorescence imaging acquisition, and Vincent Baylac (CIRIMATNNC OVM RTS) for his help in the topographical analysis.

\section{Appendix A. Supplementary data}

Supplementary data to this article can be found online at https://doi. org/10.1016/j.bioelechem.2019.03.002.

\section{References}

[1] S. Bajracharya, M. Sharma, G. Mohanakrishna, X. Dominguez Benneton, D.P.B.T.B. Strik, P.M. Sarma, D. Pant, An overview on emerging bioelectrochemical systems (BESs): technology for sustainable electricity, waste remediation, resource recovery, chemical production and beyond, Renew. Energy 98 (2016) 153-170, https://doi. org/10.1016/j.renene.2016.03.002.

[2] U. Schröder, F. Harnisch, Life electric-nature as a blueprint for the development of microbial electrochemical technologies, Joule. 1 (2017) 244-252, https://doi.org/ 10.1016/j.joule.2017.07.010.

[3] H. Wang, Z.J. Ren, A comprehensive review of microbial electrochemical systems as a platform technology, Biotechnol. Adv. 31 (2013) 1796-1807, https://doi.org/10. 1016/j.biotechadv.2013.10.001

[4] C. Santoro, C. Arbizzani, B. Erable, I. Ieropoulos, Microbial fuel cells: from fundamentals to applications. A review, J. Power Sources 356 (2017) 225-244, https://doi.org/ 10.1016/j.jpowsour.2017.03.109.

[5] A. Escapa, R. Mateos, E.J. Martínez, J. Blanes, Microbial electrolysis cells: an emerging technology for wastewater treatment and energy recovery. From laboratory to pilot plant and beyond, Renew. Sust. Energ. Rev. 55 (2016) 942-956, https://doi.org/10. 1016/j.rser.2015.11.029.

[6] F. Geppert, D. Liu, M. van Eerten-Jansen, E. Weidner, C. Buisman, A. ter Heijne, Bioelectrochemical power-to-gas: state of the art and future perspectives, Trends Biotechnol. 34 (2016) 879-894, https://doi.org/10.1016/j.tibtech.2016.08.010.

[7] X. Dominguez-Benetton, J.C. Varia, G. Pozo, O. Modin, A. Ter Heijne, J. Fransaer, K Rabaey, Metal recovery by microbial electro-metallurgy, Prog. Mater. Sci. 94 (2018) 435-461, https://doi.org/10.1016/j.pmatsci.2018.01.007.

[8] B. Erable, L. Etcheverry, A. Bergel, From microbial fuel cell (MFC) to microbial electrochemical snorkel (MES): maximizing chemical oxygen demand (COD) removal from wastewater, Biofouling 27 (2011) 319-326, https://doi.org/10.1080/ 08927014.2011.564615.

[9] A. Prévoteau, K. Rabaey, Electroactive biofilms for sensing: reflections and perspectives, ACS Sens. 2 (2017) 1072-1085, https://doi.org/10.1021/acssensors.7b00418.

[10] G. Pasternak, J. Greenman, I. Ieropoulos, Self-powered, autonomous biological oxygen demand biosensor for online water quality monitoring, Sens. Actuators B Chem. 244 (2017) 815-822, https://doi.org/10.1016/j.snb.2017.01.019.

[11] M. Mehanna, R. Basseguy, M.-L. Delia, A. Bergel, Role of direct microbial electron transfer in corrosion of steels, Electrochem. Commun. 11 (2009) 568-571, https:// doi.org/10.1016/j.elecom.2008.12.019.

[12] M. Mehanna, R. Basseguy, M.-L. Delia, A. Bergel, Geobacter sulfurreducens can protect $304 \mathrm{~L}$ stainless steel against pitting in conditions of low electron acceptor concentrations, Electrochem. Commun. 12 (2010) 724-728, https://doi.org/10.1016/j. elecom.2010.03.017.

[13] A. Mollica, P. Cristiani, On-line biofilm monitoring by "biox" electrochemical probe, Water Sci. Technol. 47 (2003) 45-49, https://doi.org/10.2166/wst.2003.0277.

[14] S. Dulon, S. Parot, M.-L. Delia, A. Bergel, Electroactive biofilms: new means for elec trochemistry, J. Appl. Electrochem. 37 (2007) 173-179, https://doi.org/10.1007/ s10800-006-9250-8.

[15] G. Pavanello, M. Faimali, M. Pittore, A. Mollica, A. Mollica, A. Mollica, Exploiting a new electrochemical sensor for biofilm monitoring and water treatment optimization, Water Res. 45 (2011) 1651-1658, https://doi.org/10.1016/j.watres.2010.12. 003.

[16] N. Chabert, O. Amin Ali, W. Achouak, All ecosystems potentially host electrogenic bacteria, Bioelectrochem. 106 ( (2015) 88-96, https://doi.org/10.1016/j. bioelechem.2015.07.004.

[17] C. Koch, F. Harnisch, Is there a specific ecological niche for electroactive microorganisms? ChemElectroChem 3 (2016) 1282-1295, https://doi.org/10.1002/celc. 201600079.

[18] A. ter Heijne, H.V.M. Hamelers, M. Saakes, C.J.N. Buisman, Performance of nonporous graphite and titanium-based anodes in microbial fuel cells, Electrochim. Acta 53 (2008) 5697-5703, https://doi.org/10.1016/j.electacta.2008.03.032.

[19] J.-J. Sun, H.-Z. Zhao, Q.-Z. Yang, J. Song, A. Xue, A novel layer-by-layer self-assembled carbon nanotube-based anode: preparation, characterization, and application in microbial fuel cell, Electrochim. Acta 55 (2010) 3041-3047, https://doi.org/10.1016/j. electacta.2009.12.103.

[20] L. Peng, S.-J. You, J.-Y. Wang, Carbon nanotubes as electrode modifier promoting direct electron transfer from Shewanella oneidensis, Biosens. Bioelectron. 25 (2010) 1248-1251, https://doi.org/10.1016/j.bios.2009.10.002.

[21] Y. Fan, S. Xu, R. Schaller, J. Jiao, F. Chaplen, H. Liu, Nanoparticle decorated anodes for enhanced current generation in microbial electrochemical cells, Biosens. Bioelectron. 26 (2011) 1908-1912, https://doi.org/10.1016/j.bios.2010.05.006.

[22] D. Pocaznoi, A. Calmet, L. Etcheverry, B. Erable, A. Bergel, Stainless steel is a promising electrode material for anodes of microbial fuel cells, Energy Environ. Sci. 5 (2012) 9645-9652, https://doi.org/10.1039/C2ee22429A

[23] L. Pons, M.-L. Délia, A. Bergel, Effect of surface roughness, biofilm coverage and biofilm structure on the electrochemical efficiency of microbial cathodes, Bioresour. Technol. 102 (2011) 2678-2683, https://doi.org/10.1016/j.biortech.2010.10.138.

[24] Z. Ye, J. Hou, M.W. Ellis, B. Behkam, Effect of anode surface roughness on power generation in microbial fuel cells, 2012 1409-1414, https://doi.org/10.1115/ IMECE2012-88643.

[25] B. Maestro, J.M. Ortiz, G. Schrott, J.P. Busalmen, V. Climent, J.M. Feliu, Crystallographic orientation and electrode nature are key factors for electric current generation by Geobacter sulfurreducens, Bioelectrochemistry. 98 (2014) 11-19, https:// doi.org/10.1016/j.bioelechem.2014.02.001.

[26] S. Kalathil, D. Pant, Nanotechnology to rescue bacterial bidirectional extracellular electron transfer in bioelectrochemical systems, RSC Adv. 6 (2016) 30582-30597, https://doi.org/10.1039/c6ra04734c. 
[27] P. Champigneux, M.-L. Delia, A. Bergel, Impact of electrode micro- and nanoscale topography on the formation and performance of microbial electrodes, Biosens. Bioelectron. 118 (2018) 231-246, https://doi.org/10.1016/j.bios. 2018.06.059.

[28] C. Dumas, R. Basseguy, A. Bergel, DSA to grow electrochemically active biofilms of Geobacter sulfurreducens, Electrochim. Acta 53 (2008) 3200-3209, https://doi. org/10.1016/j.electacta.2007.10.066.

[29] K. Guo, B.C. Donose, A.H. Soeriyadi, A. Prévoteau, S.A. Patil, S. Freguia, J.J. Gooding, K. Rabaey, Flame oxidation of stainless steel felt enhances anodic biofilm formation and current output in bioelectrochemical systems, Environ. Sci. Technol. 48 (2014) 7151-7156, https://doi.org/10.1021/es500720g.

[30] C.P.B. Siu, M. Chiao, A microfabricated PDMS microbial fuel cell, J. Microelectromech. Syst. 17 (2008) 1329-1341, https://doi.org/10.1109/JMEMS.2008.2006816.

[31] S. Inoue, E.A. Parra, A. Higa, Y. Jiang, P. Wang, C.R. Buie, J.D. Coates, L. Lin, Structural optimization of contact electrodes in microbial fuel cells for current density enhancements, Sens. Actuators Phys. 177 (2012) 30-36, https://doi.org/10.1016/j. sna.2011.09.023.

[32] T. Kano, E. Suito, K. Hishida, N. Miki, Effect of microscale surface geometry of electrodes on performance of microbial fuel cells, Jpn. J. Appl. Phys. 51 (2012) 06FK04, https://doi.org/10.1143/JJAP.51.06FK04.

[33] J. Kim, J. Hwan Ko, J. Lee, M. Jun Kim, D. Byun, Power enhancement of a $\mu$ l-scale microbial fuel cells by surface roughness, Appl. Phys. Lett. 104 (2014), 223702. https:/ doi.org/10.1063/1.4880596

[34] P. Champigneux, C. Renault-Sentenac, D. Bourrier, C. Rossi, M.-L. Delia, A. Bergel, Effect of surface nano/micro-structuring on the early formation of microbial anodes with Geobacter sulfurreducens: experimental and theoretical approaches, Bioelectrochemistry 121 (2018) 191-200, https://doi.org/10.1016/j.bioelechem. 2018.02.005.

[35] M. Chiao, K.B. Lam, L. Lin, Micromachined microbial and photosynthetic fuel cells, J. Micromechan. Microeng. 16 (2006) 2547, https://doi.org/10.1088/0960-1317/16/ $12 / 005$.

[36] H. Richter, K. McCarthy, K.P. Nevin, J.P. Johnson, V.M. Rotello, D.R. Lovley, Electricity generation by Geobacter sulfurreducens attached to gold electrodes, Langmuir. 24 (2008) 4376-4379, https://doi.org/10.1021/la703469y.

[37] Y. Liu, H. Kim, R. Franklin, D.R. Bond, Gold line array electrodes increase substrate affinity and current density of electricity-producing G. sulfurreducens biofilms, Energy Environ. Sci. 3 (2010) 1782-1788, https://doi.org/10.1039/COEE00242A.

[38] N.S. Malvankar, M. Vargas, K.P. Nevin, A.E. Franks, C. Leang, B.-C. Kim, K. Inoue, T. Mester, S.F. Covalla, J.P. Johnson, V.M. Rotello, M.T. Tuominen, D.R. Lovley, Tunable metallic-like conductivity in microbial nanowire networks, Nat. Nanotechnol. 6 (2011)https://doi.org/10.1038/nnano.2011.119 nnano.2011.119.

[39] D.R. Bond, D.R. Lovley, Electricity production by geobacter sulfurreducens attached to electrodes, Appl. Environ. Microbiol. 69 (2003) 1548-1555, https://doi.org/10. 1128/AEM.69.3.1548-1555.2003.

[40] L.D. Burke, P.F. Nugent, The electrochemistry of gold: I the redox behaviour of the metal in aqueous media, Gold Bull. 30 (1997) 43-53, https://doi.org/10.1007/ BF03214756

[41] K.A. Marcus, I. Torres César, E. Rittmann Bruce, Conduction-based modeling of the biofilm anode of a microbial fuel cell, Biotechnol. Bioeng. 98 (2007) 1171-1182, https://doi.org/10.1002/bit.21533.

[42] M. Rimboud, E. Desmond-Le Quemener, B. Erable, T. Bouchez, A. Bergel, Multisystem Nernst-Michaelis-Menten model applied to bioanodes formed from sewage sludge, Bioresour. Technol. 195 (2015) 162-169, https://doi.org/10.1016/j.biortech. 2015.05.069.

[43] W.G. Characklis, K.C. Marshall, Biofilms, Wiley, New York, 1990.
[44] K.J. Edwards, A.D. Rutenberg, Microbial response to surface microtopography: the role of metabolism in localized mineral dissolution, Chem. Geol. 180 (2001) 19-32, https://doi.org/10.1016/S0009-2541(01)00303-5.

[45] C. Díaz, P. Schilardi, M.F.L. De Mele, Influence of surface sub-micropattern on the adhesion of Pioneer Bacteria on metals, Artif. Organs 32 (2008) 292-298, https://doi. org/10.1111/j.1525-1594.2008.00545.x.

[46] F.A. Alatraktchi, Y. Zhang, J.S. Noori, I. Angelidaki, Surface area expansion of electrodes with grass-like nanostructures and gold nanoparticles to enhance electricity generation in microbial fuel cells, Bioresour. Technol. 123 (2012) 177-183, https:// doi.org/10.1016/j.biortech.2012.07.048.

[47] X. Jia, Z. He, X. Zhang, X. Tian, Carbon paper electrode modified with TiO2 nanowires enhancement bioelectricity generation in microbial fuel cell, Synth. Met. 215 (2016) 170-175, https://doi.org/10.1016/j.synthmet.2016.02.015.

[48] H. Feng, Y. Liang, K. Guo, W. Chen, D. Shen, L. Huang, Y. Zhou, M. Wang, Y. Long, TiO2 nanotube arrays modified titanium: a stable, scalable, and cost-effective bioanode for microbial fuel cells, Environ. Sci. Technol. Lett. 3 (2016) 420-424, https://doi. org/10.1021/acs.estlett.6b00410.

[49] J.R. Rumble, CRC Handbook of Chemistry and Physics, 98th edition CRC Press/Taylor \& Francis, Boca Raton, 2018https://www.crcpress.com/CRC-Handbook-of-Chemistry-and-Physics-98th-Edition/Rumble-Haynes/p/book/9781498784542, Accessed date: 27 November 2017.

[50] E. Kipf, R. Zengerle, J. Gescher, S. Kerzenmacher, How does the choice of anode material influence electrical performance? A comparison of two microbial fuel cell model organisms, ChemElectroChem. 1 (2014) 1849-1853, https://doi.org/10. 1002/celc.201402036.

[51] E. Blanchet, B. Erable, M.-L. De Solan, A. Bergel, Two-dimensional carbon cloth and three-dimensional carbon felt perform similarly to form bioanode fed with food waste, Electrochem. Commun. 66 (2016) 38-41, https://doi.org/10.1016/j.elecom. 2016.02.017.

[52] C. Santoro, M. Guilizzoni, J.P. Correa Baena, U. Pasaogullari, A. Casalegno, B. Li, S. Babanova, K. Artyushkova, P. Atanassov, The effects of carbon electrode surface properties on bacteria attachment and start up time of microbial fuel cells, Carbon 67 (2014) 128-139, https://doi.org/10.1016/j.carbon.2013.09.071.

[53] B. Li, J. Zhou, X. Zhou, X. Wang, B. Li, C. Santoro, M. Grattieri, S. Babanova, K. Artyushkova, P. Atanassov, A.J. Schuler, Surface modification of microbial fuel cells anodes: approaches to practical design, Electrochim. Acta 134 (2014) 116-126, https://doi.org/10.1016/j.electacta.2014.04.136.

[54] C.P.B. Siu, M. Chiao, A microfabricated PDMS microbial fuel cell, J. Microelectromech. Syst. 17 (2008) 1329-1341, https://doi.org/10.1109/JMEMS.2008.2006816.

[55] J. Kim, J. Hwan Ko, J. Lee, M. Jun Kim, D. Byun, Power enhancement of a $\mu \mathrm{l}$-scale microbial fuel cells by surface roughness, Appl. Phys. Lett. 104 (2014), 223702. https:// doi.org/10.1063/1.4880596.

[56] M. Oliot, S. Galier, H. Roux de Balmann, A. Bergel, Ion transport in microbial fuel cells: key roles, theory and critical review, Appl. Energy 183 (2016) 1682-1704, https://doi.org/10.1016/j.apenergy.2016.09.043.

[57] D. Pocaznoi, B. Erable, M.-L. Délia, A. Bergel, Ultra microelectrodes increase the current density provided by electroactive biofilms by improving their electron transport ability, Energy Environ. Sci. 5 (2012) 5287-5296, https://doi.org/10.1039/ C2ee01469b.

[58] M. Dopson, G. Ni, T.H.A. Sleutels, Possibilities for extremophilic microorganisms in microbial electrochemical systems, FEMS Microbiol. Rev. 40 (2016) 164-181, https://doi.org/10.1093/femsre/fuv044.

[59] C. moß, S.A. Patil, U. Schröder, Scratching the surface - how decisive are microscopic surface strutures on growth and performance of electrochemically active bacteria? Front. Energy Res. (2019). 